\title{
Identification of Patients With Variants in TPMT and Dose Reduction Reduces Hematologic Events During Thiopurine Treatment of Inflammatory Bowel Disease
}

\author{
Marieke J. H. Coenen, ${ }^{1, \star}$ Dirk J. de Jong, ${ }^{2, \star}$ Corine J. van Marrewijk, ${ }^{1, \star}$ Luc J. J. Derijks, ${ }^{3}$ \\ Sita H. Vermeulen, ${ }^{1,4}$ Dennis R. Wong, ${ }^{5}$ Olaf H. Klungel, ${ }^{6}$ Andre L. M. Verbeek, ${ }^{4}$ \\ Piet M. Hooymans, ${ }^{5}$ Wilbert H. M. Peters, ${ }^{2}$ Rene H. M. te Morsche, ${ }^{2}$ William G. Newman, ${ }^{7}$ \\ Hans Scheffer, ${ }^{8, \S}$ Henk-Jan Guchelaar, ${ }^{9, \S}$ and Barbara Franke ${ }^{8,10, \S}$
}

${ }^{1}$ Department of Human Genetics, Radboud Institute for Health Sciences, Radboud university medical center, Nijmegen, The Netherlands; ' Department of Gastroenterology, Radboud Institute for Molecular Life Sciences, Radboud university medical center, Nijmegen, The Netherlands; ${ }^{3}$ Department of Clinical Pharmacy, Máxima Medical Centre, Veldhoven, The Netherlands; ${ }^{4}$ Radboud Institute for Health Sciences, Radboud university medical center, Nijmegen, The Netherlands; ${ }^{5}$ Department of Clinical Pharmacy and Toxicology, Orbis Medical Center, Sittard-Geleen, The Netherlands; ${ }^{6}$ Department of Pharmacoepidemiology and Pharmacotherapy, Utrecht Institute of Pharmaceutical Sciences, Utrecht University, Utrecht, The Netherlands; ${ }^{7}$ Centre for Genomic Medicine, St Mary's Hospital, Manchester Academic Health Science Centre, University of Manchester, Manchester, United Kingdom; ${ }^{8}$ Department of Human Genetics, Donders Centre for Neuroscience, Radboud university medical center, Nijmegen, The Netherlands; ${ }^{9}$ Department of Clinical Pharmacy and Toxicology, Leiden University Medical Center, Leiden, The Netherlands; and ${ }^{10}$ Department of Psychiatry, Donders Centre for Neuroscience, Radboud university medical center, Nijmegen, The Netherlands

\section{See editorial on page 850 .}

BACKGROUND \& AIMS: More than $20 \%$ of patients with inflammatory bowel disease (IBD) discontinue thiopurine therapy because of severe adverse drug reactions (ADRs); leukopenia is one of the most serious ADRs. Variants in the gene encoding thiopurine S-methyltransferase (TPMT) alter its enzymatic activity, resulting in higher levels of thiopurine metabolites, which can cause leukopenia. We performed a prospective study to determine whether genotype analysis of TPMT before thiopurine treatment, and dose selection based on the results, affects the outcomes of patients with IBD. METHODS: In a study performed at 30 Dutch hospitals, patients were assigned randomly to groups that received standard treatment (control) or pretreatment screening (intervention) for 3 common variants of TPMT (TPMT*2, TPMT*3A, and TPMT*3C). Patients in the intervention group found to be heterozygous carriers of a variant received $50 \%$ of the standard dose of thiopurine (azathioprine or 6-mercaptopurine), and patients homozygous for a variant received $0 \%-10 \%$ of the standard dose. We compared, in an intention-to-treat analysis, outcomes of the intervention $(\mathrm{n}=405)$ and control groups $(\mathrm{n}=378)$ after 20 weeks of treatment. Primary outcomes were the occurrence of hematologic ADRs (leukocyte count $<3.0 * 10^{9} / \mathrm{L}$ or reduced platelet count $<100^{*} 10^{9} / \mathrm{L}$ ) and disease activity (based on the Harvey-Bradshaw Index for Crohn's disease $[n=356]$ or the partial Mayo score for ulcerative colitis [ $\mathrm{n}=253])$. RESULTS: Similar proportions of patients in the intervention and control groups developed a hematologic ADR $(7.4 \%$ vs $7.9 \%$; relative risk, 0.93 ; 95\% confidence interval, $0.57-1.52$ ) in the 20 weeks of follow-up evaluation; the groups also had similar mean levels of disease activity $(P=.18$ for Crohn's disease and $P=.14$ for ulcerative colitis). However, a significantly smaller proportion of carriers of the TPMT variants in the intervention group $(2.6 \%)$ developed hematologic ADRs compared with patients in the control group $(22.9 \%)$ (relative risk, 0.11 ; 95\% confidence interval, 0.01-0.85). CONCLUSIONS: Screening for variants in TPMT did not reduce the proportions of patients with hematologic ADRs during thiopurine treatment for IBD. However, there was a 10-fold reduction in hematologic ADRs among variant carriers who were identified and received a dose reduction, compared with variant carriers who did not, without differences in treatment efficacy. ClinicalTrials.gov number: NCT00521950.

Keywords: Leukocyte; Adverse Event; Pharmacogenetic; Side Effect.

7 hiopurines are effective to induce and maintain longterm remission in up to $70 \%$ of patients with inflammatory bowel disease (IBD) (Crohn's disease [CD] and ulcerative colitis [UC]). ${ }^{1}$ Azathioprine and 6-mercaptopurine are inactive prodrugs that need to undergo intracellular conversion to pharmacologically active 6-thioguanine nucleotides before exerting their cytotoxic action on (overactive) immune cells. Thiopurine S-methyltransferase (TPMT) metabolizes thiopurines to inactive metabolites, leaving less

*Authors share co-first authorship; ${ }^{\S}$ Authors share co-senior authorship.

Abbreviations used in this paper: ADR, adverse drug reaction; CD, Crohn's disease; CRP, C-reactive protein; ESR, erythrocyte sedimentation rate; HBI, Harvey-Bradshaw Index; IBD, inflammatory bowel disease; RBC, red blood cell; TOPIC, Thiopurine response Optimization by Pharmacogenetic testing in Inflammatory bowel disease Clinics; TPMT, thiopurine S-methyltransferase; UC, ulcerative colitis.

(D) Most current article

(C) 2015 by the AGA Institute 0016-5085/\$36.00

http://dx.doi.org/10.1053/j.gastro.2015.06.002 
parent drug to be metabolized to active 6-thioguanine nucleotides. ${ }^{2,3}$ Approximately $10 \%$ of Caucasians carry a genetic variant in the TPMT gene, resulting in decreased TPMT enzyme activity and consequently higher 6-thioguanine nucleotide levels and a higher risk of potentially lifethreatening myelosuppression during thiopurine treatment. ${ }^{4}$

More than $20 \%$ of IBD patients discontinue thiopurine treatment owing to (serious) adverse drug events. ${ }^{5,6}$ Current guidelines for thiopurine treatment mandate regular hematologic monitoring to detect (severe) myelotoxicity, most commonly presenting as leukopenia and to a lesser extent as thrombocytopenia. ${ }^{1}$ However, this is not a complete safeguard because myelotoxicity can develop suddenly at any time point during treatment, and patients with bone marrow suppression have a higher cumulative incidence of infections, mortality, and death. ${ }^{1,7}$ This underscores the importance of treating patients as safely as possible (ie, based on genotype) from treatment start. Pharmacogenetic testing for TPMT has been advocated for a long time to optimize the safety of thiopurine treatment, but clinical use of pretreatment TPMT testing has been low, and effectiveness data are lacking. ${ }^{8}$ To date, 2 TPMT-related, randomized, controlled trials have been performed, one including patients with a range of inflammatory conditions, but mainly IBD ( $85 \%$ of the patients included), the other study including 29 IBD patients. Definitive conclusions could not be drawn from either study. ${ }^{9,10}$ A recent meta-analysis ( $\mathrm{n}=$ 4306 patients) suggested that IBD patients with decreased TPMT activity are indeed at increased risk of developing leukopenia compared with patients with normal TPMT activity. $^{3}$

In general, pharmacogenetic testing to optimize treatment is applied only on a limited scale in clinical practice to date because large-scale, randomized, controlled trials proving the effectiveness of available tests largely are lacking. ${ }^{11-13}$ This also is hampering for the clinical uptake of TPMT testing before thiopurine treatment. In this randomized controlled trial (Thiopurine response Optimization by Pharmacogenetic testing in Inflammatory bowel disease Clinics [TOPIC]), we investigated whether pretreatment TPMT genotyping followed by personalized dosing results in a reduced incidence of hematologic adverse drug reactions (ADRs). In addition, we evaluated the influence of this safety optimizing strategy on clinical outcome and other ADRs.

\section{Materials and Methods}

\section{Patients}

Patients were assessed for eligibility by their gastroenterologist. Patients who met the inclusion criteria were assigned randomly to pretreatment TPMT genotyping (intervention group) or standard treatment (control group). Inclusion criteria were as follows: age older than 18 years and a diagnosis of IBD. Exclusion criteria were as follows: previous use of azathioprine or 6-mercaptopurine, co-treatment with allopurinol, leukocyte count less than $3.0^{*} 10^{9} / \mathrm{L}$, liver test abnormalities (liver enzyme levels [alanine aminotransferase, aspartate aminotransferase, alkaline phosphatase, and/or $\gamma$-glutamate transpeptidase] $\geq 2$ times normal upper limit), reduced renal function (creatinine serum level $\geq 2$ times normal upper limit), known TPMT enzyme activity or genotype, and current pregnancy.

The study protocol was approved by the Institutional Review Board of the Radboud university medical center (Commissie Mensgebonden Onderzoek Regio Arnhem Nijmegen, protocol number: 13171), approval for inclusion of patients in other institutes was obtained from institutional ethics committee. All patients provided written informed consent. This study is registered at clinicaltrials.gov (NCT00521950).

\section{Study Design}

Thirty Dutch hospitals participated in the parallel randomized controlled trial. Patients were enrolled by the TOPIC recruitment team (see Acknowledgment section for a list of TOPIC collaborators). Randomization was based on a computer-generated schedule per participating center with a block size of 4 (developed by C.J.v.M.). Gastroenterologists and patients were blinded to randomization. All authors had access to the study data and have reviewed and approved the final manuscript.

Blood samples for TPMT genotyping and enzyme measurements were collected from every patient before treatment initiation, and were numbered upon arrival at the laboratory. Only patients assigned to the intervention group underwent pretreatment testing for 3 common TPMT variants (TPMT*2 [238G $>$ C (rs1800462)], TPMT*3A [460G $>$ A (rs1800460) and 719A $>$ G (rs1142345)], and TPMT*3C [rs1142345]), accounting for approximately $95 \%$ of the variant alleles observed in Caucasians. ${ }^{5,14,15}$ The turn-around time for genotyping results (intervention group) and dosing advice (all patients) was 5 working days. Patients in the control group and patients who did not carry a TPMT variant were treated according to standard IBD guidelines $(2-2.5 \mathrm{mg} / \mathrm{kg} /$ day azathioprine or $1-1.5$ $\mathrm{mg} / \mathrm{kg} /$ day 6-mercaptopurine). Patients in the intervention group who carried a genetic variant received $50 \%$ (heterozygotes) or $0 \%-10 \%$ (homozygotes) of the standard thiopurine dose according to the evidence-based guidelines of the Dutch Pharmacogenetics Working Group. ${ }^{16}$ For all patients (intervention and control groups) a letter containing the dose advice was sent to the gastroenterologist. The majority of the patients ( $\mathrm{n}=705 ; 90 \%$ ) received advice for the standard dose according to the Dutch guidelines. The study was not blinded. Gastroenterologists were allowed to change the thiopurine dose or stop treatment when a side effect occurred. The following guidelines were provided: consider a dose reduction by a count of $4^{*} 10^{9} / \mathrm{L}$ or less and a fast decrease of leukocyte count, dose reduction of $50 \%$ by a leukocyte count of $3 * 10^{9} / \mathrm{L}$ or less, and treatment stop by a leukocyte count of less than $1 * 10^{9} / \mathrm{L}$. Treatment re-challenge was at the discretion of the gastroenterologist.

The primary outcome of the study was the development of a hematological ADR. Secondary outcomes based on blood levels were signs of hepatotoxicity, pancreatitis, or anemia. Secondary outcomes reported by clinicians included general side effects (dizziness, shivers, fever, general malaise), gastrointestinal side effects (stomach ache, diarrhea, reduced appetite, nausea, and vomiting), hepatic side effects (cholestasis, cholangitis, hepatitis, and steatosis), dermatological side-effects (hair loss, warts, and skin rash), myalgia, and arthralgia. Included patients were followed up for 20 weeks after thiopurine treatment initiation. 
Blood for biochemical measurements was collected at least 1 week before study start and at weeks 1, 2, 4, 6, 8, and 20. Erythrocyte sedimentation rate (ESR) and C-reactive protein (CRP) levels were measured before treatment start and at $20 \pm 6$ weeks. Leukocytes, thrombocytes, hemoglobin, hematocrit, mean corpuscular volume, liver enzymes (alanine aminotransferase, aspartate aminotransferase, alkaline phosphatase, and $\gamma$-glutamate transpeptidase), and amylase or lipase were measured at every visit. At week 8, blood samples were collected for 6-thioguanine nucleotide and 6methylmercaptopurine ribonucleotide metabolite measurement; metabolites were assessed after follow-up evaluation.

Clinical evaluation was performed before study start and at week $20 \pm 6$ weeks to determine disease location and activity. During the follow-up period, clinical information (complications and changes in treatment such as changes of azathioprine/6-mercaptopurine dose or co-medication) was collected when patients had contact with the gastroenterologist, timing and intervals of which were at the discretion of the clinician. Patients received questionnaires concerning disease activity (number of [liquid] stools, abdominal pain, fever, use of antidiarrheal medication, general well-being) 1 week before treatment initiation and at week 20 . These data, in combination with clinical measures, were used to calculate the disease activity (Harvey-Bradshaw Index [HBI] for CD and partial Mayo for UC). For the HBI, we used abdominal mass measured before treatment initiation in case this measure was missing at 20 weeks.

\section{Genotyping}

Genetic analysis was performed in a IS015189-accredited laboratory (Human Genetics Department, Radboud university medical center, Nijmegen, The Netherlands). Genotyping of 3 common TPMT variants (TPMT*2, TPMT*3A, and TPMT*3C, UCSC Genome Browser [genome.ucsc.edu] accession number: NM_000367.3) was performed using TaqMan SNP genotyping assays according to the manufacturer protocol (Life Technologies, Bleiswijk, The Netherlands: rs1800462: assayID:C_12091552_30; rs1800460: assay-ID:C_30634116_20; and rs1142345: assay-ID:C__19567_20). Signals were detected with the 7500 Fast Real-Time Polymerase Chain Reaction System (Life Technologies) and subsequently analyzed using Allelic Discrimination software version 1.4 (Life Technologies). All patients in the intervention arm were genotyped in triplicate. Patients assigned to the control group were genotyped in one batch in duplicate after the follow-up period of 20 weeks. Each genotyping experiment contained at least 4 positive controls for each TPMT variant. Five percent of samples were genotyped in duplicate (within or between plates); all genotypes were concordant. Sequencing of the protein coding part of the TPMT gene was performed in a subset of patients (Supplementary Table 1).

\section{Enzyme and Metabolite Measurements}

TPMT enzyme activity and thiopurine metabolites were assessed after the follow-up period had ended. Blood for TPMT enzyme activity measurements was collected before treatment initiation and stored at $-80^{\circ} \mathrm{C}$ until further processing. Enzyme activity was measured in red blood cells (RBCs) using a high-performance liquid chromatography method described previously. ${ }^{17}$
Blood samples for 6-thioguanine nucleotide and 6methylmercaptopurine ribonucleotide measurement were stored immediately at $2^{\circ} \mathrm{C}-8^{\circ} \mathrm{C}$ and sent to the Department of Clinical Pharmacy and Toxicology (Orbis Medical Centre, Sittard-Geleen, The Netherlands), where samples were processed and stored at $-20^{\circ} \mathrm{C}$ until required. 6-Thioguanine nucleotides and 6-methylmercaptopurine ribonucleotides levels were determined with a modified high-performance liquid chromatography method as published previously. ${ }^{18}$ Lower limits of quantification for 6-thioguanine nucleotide and 6-methylmercaptopurine ribonucleotide metabolite levels were $40 \mathrm{pmol} / 8 \times 10^{8} \mathrm{RBCs}$ and $300 \mathrm{pmol} / 8 \times 10^{8} \mathrm{RBCs}$, respectively. Interassay variability for both 6-thioguanine nucleotides and 6-methylmercaptopurine ribonucleotides was less than $10 \%$.

\section{Statistical Analysis}

The study was designed to have $80 \%$ power with inclusion of 388 patients per treatment arm and a reduction in hematologic ADR rate of $50 \%$ (hematologic ADR rate of $11 \%$ in the nongenotyped group and $5.5 \%$ in the genotyped group; 2 -sided $P$ value threshold was .05).

The data set was analyzed on an intention-to-treat basis after exclusion of patients who were lost to follow-up evaluation (Supplementary Figure 1). Differences in baseline variables and ADRs between patients grouped as intervention or control were assessed using the Pearson $\mathrm{X}^{2}$ test, the Fisher exact test, the Student $t$ test, the Mann-Whitney $U$ test, or an independent sample Kruskal-Wallis test, as appropriate. Hardy-Weinberg equilibrium was assessed using a $\mathrm{X}^{2}$ test. Primary outcomes of the study were as follows: (1) occurrence of hematologic ADRs defined as a leukocyte count of $3.0^{*} 10^{9} / \mathrm{L}$ or less (which is indicative of an increased risk for serious systemic infections) within the follow-up period of $20 \pm 6$ weeks, or platelet count less than $100 * 10^{9} / \mathrm{L}$; and (2) clinical outcome based on disease activity scores. Secondary outcomes were the occurrence of other (severe) ADRs. Post hoc comparisons for patients with and without a variant between the intervention and control groups were performed for the primary outcome hematologic ADRs using the Pearson $\mathrm{X}^{2}$ test. Analyses were performed using IBM SPSS Statistics for Windows, Version 20.0 (release 20.0.0.1; IBM Corp, Armonk, NY).

\section{Results}

Patients were included from October 2007 until December 2010 and followed up for a period of 20 weeks; 796 eligible patients were randomized (Supplementary Figure 1). Final analyses included 405 patients from the intervention group and 378 patients from the control group (Supplementary Figure 1). Baseline characteristics of the intervention and control groups did not show statistically significant differences (Table 1 and Supplementary Table 2) except for the biologics used as co-medication at the study start (intervention group, 3.7\%; control group, 7.4\%; $P=$ .027). Steroid use, the main co-medication for patients with IBD, was similar for both groups during follow-up evaluation (Supplementary Table 3). Overall, the thiopurine dose was similar for the intervention and control groups (Supplementary Table 4). Fifty-five (13.6\%) patients in the 
Table 1. Characteristics of the Study Population

\begin{tabular}{|c|c|c|c|}
\hline & Total & Intervention group & Control group \\
\hline Total & $783(100 \%)$ & 405 (100\%) & $378(100 \%)$ \\
\hline Male, $\mathrm{n}$ & 354 (45.2\%) & $186(45.9 \%)$ & $168(44.4 \%)$ \\
\hline Age, $y$ (SD) & $41.0(15.8)$ & $41.6(15.9)$ & $40.5(15.8)$ \\
\hline Weight, $k g$ (SD) & $74.3(16.2)^{a}$ & $73.9(16.3)$ & 74.7 (16.2) \\
\hline Age of disease onset, $y$ (SD) & $35.7(15.1)^{a}$ & $36.3(15.4)$ & $35.0(14.8)^{b}$ \\
\hline $\begin{array}{l}\text { Disease duration until treatment start, } \\
\text { median (minimum-maximum), } y\end{array}$ & $1.2(0-49.7)^{a}$ & $1.3(0-45.0)$ & $1.1(0-49.7)^{b}$ \\
\hline \multicolumn{4}{|l|}{ Medication, n } \\
\hline Azathioprine & 503 (64.2\%) & $256(63.2 \%)$ & 247 (65.3\%) \\
\hline 6-mercaptopurine & 279 (35.6\%) & $148(36.5 \%)$ & $131(34.7 \%)$ \\
\hline None started ${ }^{C}$ & $1(0.1 \%)$ & $1(0.3 \%)$ & $0(0 \%)$ \\
\hline \multicolumn{4}{|l|}{ Drug dose start, $\mathrm{mg} / \mathrm{kg}$} \\
\hline Azathioprine $^{c}$ & $2.0(0-3.1)$ & $2.1(0-2.7)$ & $2.2(0-3.1)$ \\
\hline 6-mercaptopurine & $1.1(0-2.2)$ & $1.2(0-2.2)$ & $1.2(0-2.0)$ \\
\hline \multicolumn{4}{|l|}{ Drug dose 20 weeks, $\mathrm{mg} / \mathrm{kg}$} \\
\hline Azathioprine & $2.1(0.5-3.1)^{d}$ & $2.1(0.5-2.7)^{e}$ & $2.2(0.6-3.1)^{f}$ \\
\hline 6-mercaptopurine & $1.0(0.3-1.5)^{9}$ & $1.1(0.3-1.5)^{h}$ & $1.1(0.4-1.5)^{h}$ \\
\hline \multicolumn{4}{|l|}{ Co-medication, $\mathrm{n}$} \\
\hline Corticosteroids & $640(81.7 \%)$ & $336(83.0 \%)$ & $304(80.4 \%)$ \\
\hline Mesalamine & $388(49.6 \%)$ & $198(48.9 \%)$ & $190(50.3 \%)$ \\
\hline Biologicals & $43(5.5 \%)$ & $15(3.7 \%)$ & $28(7.4 \%)$ \\
\hline \multicolumn{4}{|l|}{ TPMT genotype, $\mathrm{n}$} \\
\hline${ }^{*} 1 /{ }^{*} 1$ & 705 (90.0\%) & $365(90.1 \%)$ & $340(89.9 \%)$ \\
\hline${ }^{*} 1 /{ }^{*} 2$ & 7 (0.9\%) & $4(1.0 \%)$ & $3(0.8 \%)$ \\
\hline${ }^{*} 1 /{ }^{*} 3 \mathrm{~A}$ & $58(7.4 \%)$ & $31(7.7 \%)$ & $27(7.1 \%)$ \\
\hline$* 1 /{ }^{*} 3 C$ & $12(1.5 \%)$ & $4(1.0 \%)$ & $8(2.1 \%)$ \\
\hline${ }^{*} 3 \mathrm{~A} /{ }^{*} 3 \mathrm{~A}$ & $1(0.1 \%)$ & $1(0.2 \%)$ & $0(0 \%)$ \\
\hline Baseline ESR & $15(1-109)^{i}$ & $14(1-109)^{\prime}$ & $15(1-102)^{k}$ \\
\hline CD patients & $16(1-109)^{\prime}$ & $16(1-109)^{m}$ & $16(1-102)^{n}$ \\
\hline UC patients & $12.5(1-95)^{\circ}$ & $14(1-95)^{p}$ & $10(2-85)^{q}$ \\
\hline Increased baseline ESR & $270(42.7 \%)^{i}$ & $141(42.1 \%)^{j}$ & $129(43.3 \%)^{k}$ \\
\hline CD patients & $176(46.1 \%)^{\prime}$ & $91(44.4 \%)^{m}$ & $85(48.0)^{n}$ \\
\hline UC patients & $90(37.2 \%)^{\circ}$ & $50(39.1 \%)^{p}$ & $40(35.1 \%)^{q}$ \\
\hline Baseline CRP & $8(0-284)^{r}$ & $8(0.6-214)^{s}$ & $7(0-284)^{t}$ \\
\hline CD patients & $9(0.6-284)^{u}$ & $8(0.6-91)^{v}$ & $10(0.6-284)^{w}$ \\
\hline UC patients & $6(0-214)^{x}$ & $7(1-214)^{y}$ & $5(0-180)^{z}$ \\
\hline Increased baseline CRP & $277(37.4 \%)^{a a}$ & $144(37.4 \%)^{b b}$ & $133(37.5 \%)^{c c}$ \\
\hline CD patients & $194(43.2 \%)^{d d}$ & $96(40.9 \%)^{e e}$ & $98(45.8 \%)^{f f}$ \\
\hline UC patients & $78(27.8 \%)^{g g}$ & $48(32.7 \%)^{h h}$ & $30(22.4 \%)^{i i}$ \\
\hline
\end{tabular}

NOTE. Table data show means (SD), $\mathrm{n}$ (percentage), or medians (minimum-maximum) for disease duration.

${ }^{a} \mathrm{n}=781 .{ }^{b} \mathrm{n}=376 .{ }^{c}$ Patient was homozygous for a TPMT variant and did not start thiopurine medication in agreement with therapeutic recommendations, this patient was included in the azathioprine group for start dose because this was the medication planned. Other patients who did not start medication also were included in the planned medication group. ${ }^{d} \mathrm{n}=323 .{ }^{e} \mathrm{n}=162 .{ }^{f} \mathrm{n}=161 .{ }^{g} \mathrm{n}=208 .{ }^{h} \mathrm{n}=104 .{ }^{i} \mathrm{n}=633 .{ }^{j} \mathrm{n}=335 .{ }^{k} \mathrm{n}=298 .{ }^{\prime} \mathrm{n}=382 .{ }^{m} \mathrm{n}=205 .{ }^{n} \mathrm{n}=177 .{ }^{o} \mathrm{n}=242$. ${ }^{p_{\mathrm{n}}}=128 .{ }^{a} \mathrm{n}=114 .{ }^{r} \mathrm{n}=564 .{ }^{s} \mathrm{n}=294 .{ }^{t} \mathrm{n}=270 .{ }^{u} \mathrm{n}=356 .{ }^{\mathrm{v}} \mathrm{n}=185 .{ }^{w} \mathrm{n}=171 .{ }^{x} \mathrm{n}=199 .{ }^{1} \mathrm{n}=107 .{ }^{z} \mathrm{n}=92 .{ }^{a a} \mathrm{n}=740$. ${ }^{b b} \mathrm{n}=385 .{ }^{c c} \mathrm{n}=355 .{ }^{d d} \mathrm{n}=449 .{ }^{e e} \mathrm{n}=235 .{ }^{f f} \mathrm{n}=214 .{ }^{g g} \mathrm{n}=281 .{ }^{h h_{n}} \mathrm{n}=147 .{ }^{i i} \mathrm{n}=134$.

intervention group and $41(10.8 \%)$ patients in the control group did not start with the advised dose, all but 1 patient started with a lower dose (Supplementary Figure 1 and Supplementary Table 5). Two patients (1 each in the intervention and control groups) started treatment before the dose was provided and 12 patients ( 5 in the intervention group and 7 in the control group) did not start treatment at the planned time point. In addition, 1 patient in this study was homozygous for a TPMT variant and did not start treatment according to the dose advice of $0-10 \%$ of the standard thiopurine dose. The azathioprine starting dose was not different between the intervention and control groups, but a significant difference was observed in the 6mercaptopurine starting dose (Supplementary Table 4) $(P=.045)$, this could be attributed to our intervention because the dose difference was evident only in patients with a genetic variant in TPMT $(P<.004)$, patients without a variant were started on similar 6-mercaptopurine doses as patients in the control group $(P=.27)$. Thiopurine treatment was discontinued at similar rates in the intervention $(\mathrm{n}=170 ; 42.0 \%)$ and control $(\mathrm{n}=143 ; 37.8 \%)$ groups; 266 $(65.7 \%)$ and $262(69.3 \%)$ of the patients were using thiopurines for up to 20 weeks in the intervention and control groups, respectively (Supplementary Table 4). 
Table 2. Overview of the Primary and Secondary Adverse Effects That Occurred in the Study Population

\begin{tabular}{|c|c|c|c|c|c|c|c|}
\hline & \multicolumn{2}{|c|}{ Total population } & \multicolumn{2}{|c|}{ Intervention group } & \multicolumn{2}{|c|}{ Control group } & \multirow[b]{2}{*}{$\mathrm{RR}(95 \% \mathrm{Cl})$} \\
\hline & n (\%) & $\mathrm{N}$ total & $\mathrm{n}(\%)$ & $\mathrm{N}$ total & n (\%) & $\mathrm{N}$ total & \\
\hline \multicolumn{8}{|l|}{ Primary outcome } \\
\hline $\begin{array}{l}\text { Hematologic ADR } \\
\text { Secondary outcomes bas } \\
\text { on blood levels }\end{array}$ & $58(7.5)$ & 783 & $30(7.4)$ & 405 & $30(7.9)$ & 378 & $0.93(0.57-1.52)$ \\
\hline Signs of hepatotoxicity & $203(26.6)$ & 762 & $106(26.7)$ & 397 & $98(25.9)$ & 371 & $1.01(0.80-1.28)$ \\
\hline Signs of pancreatitis & $187(25.0)$ & 749 & $106(27.2)$ & 389 & $84(22.2)$ & 365 & $1.18(0.92-1.52)$ \\
\hline Signs of anemia & $474(62.1)$ & 763 & $246(61.8)$ & 398 & $231(61.1)$ & 371 & $0.99(0.89-1.11)$ \\
\hline \multicolumn{8}{|c|}{$\begin{array}{l}\text { Secondary outcomes reported } \\
\text { by clinicians }\end{array}$} \\
\hline General & $324(41.4)$ & 783 & $161(39.8)$ & 405 & $163(43.1)$ & 378 & $0.92(0.78-1.09)$ \\
\hline Dizziness & $125(16.0)$ & 783 & 59 (14.6) & 405 & 66 (17.5) & 378 & $0.83(0.60-1.15)$ \\
\hline Shivers & $67(8.6)$ & 783 & $35(8.6)$ & 405 & $32(8.5)$ & 378 & $1.02(0.65-1.61)$ \\
\hline Fever & $104(13.3)$ & 783 & $57(14.1)$ & 405 & $47(12.4)$ & 378 & $1.13(0.79-1.62)$ \\
\hline General malaise & $213(27.2)$ & 783 & 109 (26.9) & 405 & 104 (27.5) & 378 & $0.98(0.78-1.23)$ \\
\hline Gastrointestinal & $559(71.4)$ & 783 & $290(71.6)$ & 405 & $269(71.2)$ & 378 & $1.01(0.92-1.10)$ \\
\hline Stomach ache & $395(50.4)$ & 783 & $205(50.6)$ & 405 & $190(50.3)$ & 378 & $1.01(0.88-1.16)$ \\
\hline Diarrhea & $235(30.0)$ & 783 & $123(30.4)$ & 405 & $112(29.6)$ & 378 & $1.03(0.83-1.27)$ \\
\hline Reduced appetite & $160(20.4)$ & 783 & $82(20.2)$ & 405 & 78 (20.6) & 378 & $0.98(0.74-1.29)$ \\
\hline Nausea & $317(40.5)$ & 783 & $160(39.5)$ & 405 & $157(41.5)$ & 378 & $0.95(0.80-1.13)$ \\
\hline Vomiting & $120(15.3)$ & 783 & $63(15.6)$ & 405 & $57(15.1)$ & 378 & $1.03(0.74-1.43)$ \\
\hline Infections & $30(3.8)$ & 783 & $13(3.2)$ & 405 & $17(4.5)$ & 378 & $0.71(0.35-1.45)$ \\
\hline Hepatic & $54(6.9)$ & 783 & $27(6.7)$ & 405 & $27(7.1)$ & 378 & $0.93(0.56-1.56)$ \\
\hline Cholestasis & $16(2.0)$ & 783 & $8(2.0)$ & 405 & $8(2.1)$ & 378 & $0.93(0.35-2.46)$ \\
\hline Cholangitis & $3(0.4)$ & 783 & $1(0.2)$ & 405 & $2(0.5)$ & 378 & $0.47(0.04-5.13)$ \\
\hline Hepatitis & $41(5.2)$ & 783 & $21(5.2)$ & 405 & $20(5.3)$ & 378 & $0.98(0.54-1.78)$ \\
\hline Steatosis & $3(0.4)$ & 783 & $0(0)$ & 405 & $3(0.8)$ & 378 & $0.13(0.01-2.57)$ \\
\hline Dermatologic & $171(21.8)$ & 783 & $83(20.5)$ & 405 & 88 (23.3) & 378 & $0.88(0.68-1.15)$ \\
\hline Hair loss & $52(6.6)$ & 783 & $26(6.4)$ & 405 & $26(6.9)$ & 378 & $0.93(0.55-1.58)$ \\
\hline Warts & $9(1.1)$ & 783 & $5(1.2)$ & 405 & $4(1.1)$ & 378 & $0.93(0.32-4.31)$ \\
\hline Skin rash & $136(17.4)$ & 783 & $65(16.0)$ & 405 & $71(18.8)$ & 378 & $0.85(0.63-1.16)$ \\
\hline Myalgia & $114(14.6)$ & 783 & 62 (15.3) & 405 & $52(13.8)$ & 378 & $1.12(0.79-1.57)$ \\
\hline Arthralgia & 132 (16.9) & 783 & 70 (17.3) & 405 & $62(16.4)$ & 378 & $1.05(0.77-1.44)$ \\
\hline
\end{tabular}

NOTE. The following reference values were used for the side effects based on blood levels: hematologic ADR: leukocyte count $\leq 3.0^{*} 10^{9} / \mathrm{L}$ and/or platelet count $<100^{*} 10^{9} / \mathrm{L}$; signs of hepatotoxicity: at least 1 liver enzyme (alkaline phosphatase, alanine aminotransferase, aspartate aminotransferase, and/or $\gamma$-glutamate transpeptidase) more than $2 \times$ the upper limit reference value; and signs of pancreatitis: amylase and/or lipase blood level higher than the reference value. Fourteen patients (7 in each group) with signs of pancreatitis developed pancreatitis on the initially started thiopurine. Pancreatitis is defined as the presence of 2 of 3 criteria for pancreatitis (amylase or lipase levels more than $3 \times$ the upper limit reference value, stomach ache, or radiologic discrepancies). Signs of anemia were a hemoglobin level lower than the reference value.

Clinicians scored the patients for the presence of ADRs, and these were scored as present or absent on case report forms during every hospital visit of the patients. A patient was included once, in case a specific ADR was reported more than one time. In the overall groups (general, gastrointestinal, hepatic, and dermatologic side effects) presented in the table, patients might be counted more than once if they had more than one ADR in the specific group.

$\mathrm{Cl}$, confidence interval; RR, relative risk.

ADR frequencies in the first 20 weeks after thiopurine initiation are summarized in Table 2. The main outcome measure of our study, hematologic ADRs (leukocyte count $\leq 3.0^{*} 10^{9} / \mathrm{L}$ or platelet count $<100 * 10^{9} / \mathrm{L}$ ), was observed in 30 patients in the intervention and control groups. Overall, no significant differences in ADR frequencies were observed between both groups (Table 2). Two patients died. One patient was a heterozygous TPMT*3A carrier allocated to the intervention group, starting treatment according to dose advice $(1.2 \mathrm{mg} / \mathrm{kg})$, in addition to using mesalamine and prednisone. CRP was increased from 6 to $29 \mathrm{mg} / \mathrm{L}$ and the leukocyte count decreased from $5.1^{*} 10^{9} / \mathrm{L}$ to $3.6^{*} 10^{9} / \mathrm{L}$ in the 3 days before treatment initiation. Three days after treatment initiation the leukocyte count had decreased to $2.9 * 10^{9} / \mathrm{L}$, and the patient died from leukopenia resulting from Escherichia coli sepsis with pneumonia. The other patient (without a TPMT variant) started azathioprine in addition to infliximab and corticosteroids. The leukocyte count decreased to $2.5^{*} 10^{9} / \mathrm{L}$ on day 16 , and azathioprine treatment was stopped. From that moment on the patient used prednisone, methotrexate, and infliximab as immunosuppressive treatment. On day 27 the patient was hospitalized with Pneumocystis carinii pneumonia (leukocyte count, $8.0 * 10^{9} / \mathrm{L}$ ) and died on day 48 . 
Observed allele frequencies were comparable with reported frequencies (Table 1$).{ }^{15}$ One person $(0.1 \%)$ was homozygous for TPMT*3A and 77 patients $(9.8 \%)$ were heterozygous carriers of a TPMT variant. Enzyme activity measurements showed that patients carrying a genetic variant had a lower TPMT enzyme activity than patients without a variant (Supplementary Figure 2). Twelve patients without one of the pretested variants had low TPMT enzyme activity $(<60 \mathrm{mg} 6$-methylguanine/mmol hemogloblin per hour), one of the patients developed leukopenia. Complete sequencing of the TPMT gene coding region showed a known silent variant (rs2842934; Ile158Ile, TPMT*1S) in 4 of the 12 patients. ${ }^{19}$ Only 1 of these patients developed a hematologic ADR.

Thirty patients in each group developed a hematologic ADR, the majority, 29 in each group, developed leukopenia. A reduced platelet count was observed in 3 patients (2 patients also developed leukopenia) in the intervention group and in 2 patients (1 patient also developed leukopenia) in the control group. The intention-to-treat analysis showed no difference in the occurrence of hematologic ADRs between the intervention and control groups $(7.4 \%$ vs $7.9 \%$; relative risk, 0.93 ; $95 \%$ confidence interval, $0.57-1.52$ ) (Table 2). An analysis excluding patients on biologicals was performed because biological use differed between the intervention and control groups at baseline. This did not show any difference in hematologic ADRs between both groups ( $7.4 \%$ vs $6.7 \%)$. Limiting the analysis to only those patients who actually started treatment showed similar results $(7.5 \%$ vs $8.1 \%)$. In addition, we did not observe significant differences in the median time to a hematologic ADR (in those patients who developed an ADR) between the intervention (42 days; interquartile range, 69 days) and control (56 days; interquartile range, 58 days) groups, the number of patients who developed an ADR in the first 8 weeks did not differ between groups (18 in each group). Post hoc analysis of the subgroup of patients carrying a TPMT variant $\left({ }^{*} 2,{ }^{*} 3 \mathrm{~A}\right.$, or $\left.{ }^{*} 3 \mathrm{C}\right)$, which included only those patients who started treatment at the study start, showed that a personalized dose regimen based on pretreatment genotyping resulted in a statistically significant decrease in hematologic ADR occurrence $(P=.011$; relative risk, $0.11 ; 95 \%$ confidence interval, 0.01-0.85) (Table 3). In the intervention group only 1 of 39 patients carrying a TPMT variant $(2.6 \%)$ developed a hematologic ADR compared with 8 of 35 patients in the control group (22.9\%). Analysis of the subset of patients with a genetic variant who had not received biologicals $(n=69)$ also showed fewer instances of hematologic ADRs $(P=.011)$. No difference in the occurrence of hematologic ADRs between the intervention and control groups was found for the patients without a TPMT variant $(P=.47)$ (Table 3).

Several approaches were used to investigate whether a thiopurine dose reduction in the TPMT variant carriers in the intervention arm resulted in effective treatment. First, the disease activity was assessed. We did not observe statistically significant differences in clinical outcome (disease activity) between both groups at baseline in an intention-to-treat analysis $(P=.13$ for HBI; $P=.83$ for partial Mayo) and 20 weeks after treatment initiation $(P=.18$ for HBI; $P=.14$ for partial Mayo). A decrease in the median disease activity scores after 20 weeks was observed in both treatment groups, and in patients with and without the genetic variant (Figure 1). Both groups also showed similar rates of clinical remission (Supplementary Table 6). To assess treatment efficacy the change in ESR and CRP between treatment start and 20 weeks was evaluated (Supplementary Table 6). This showed a statistically significant difference for the absolute ESR change in patients with a genetic variant $(P=.042$, for the benefit of patients in the intervention group). Besides clinical outcome we also evaluated treatment efficacy by measuring 6-thioguanine nucleotide and 6methylmercaptopurine ribonucleotide metabolite levels at week 8. This was performed to investigate whether thiopurine dose reduction in TPMT variant carriers in the intervention arm resulted in effective treatment (Figure 2 and Supplementary Figure 3). Comparison of patients with a TPMT variant showed that a reduced thiopurine dose resulted in 6-thioguanine nucleotide levels within the therapeutic range, whereas a standard dose resulted in clearly increased 6-thioguanine nucleotides levels (Figure 2A). In addition, 6thioguanine nucleotides and 6-methylmercaptopurine ribonucleotide concentrations in patients without a genetic variant did not differ between the intervention and control

Table 3. Secondary Analysis: Hematologic ADR Occurrence in the Intervention and Control Groups

\begin{tabular}{lccr}
\hline & Intervention & Control & RR (95\% Cl) \\
\hline $\begin{array}{l}\text { Total, } \mathrm{n} \\
\text { Hematologic ADR }\end{array}$ & 399 & 370 & \\
$\quad$ Total & $29(7.2 \%)$ & $29(7.8 \%)$ & $0.11(0.01-0.85)$ \\
$\quad$ TPMT variant carriers & 1 of $39(2.6 \%)^{a}$ & 22 of $35(22.9 \%)$ & $1.2(0.72-2.09)$
\end{tabular}

NOTE. No deviations from Hardy-Weinberg equilibrium were observed (238G $>\mathrm{C}, P=.9 ; 460 \mathrm{G}>\mathrm{A}, P=.93 ; 719 \mathrm{~A}>\mathrm{G}, P=.67$ ). The patient homozygous TPMT ${ }^{\star} 3 A$ was randomized to the intervention group, the other patients in the intervention group were heterozygous for TPMT*2 $(n=4), T P M T^{\star} 3 A(n=30)$, or TPMT*3C $(n=4)$. The following genotypes were observed in the control group, all patients were heterozygous, TPMT ${ }^{\star} 2(n=3)$, TPMT*3A $(n=26)$, and TPMT*3C $(n=6)$. $\mathrm{Cl}$, confidence interval; $\mathrm{RR}$, relative risk.

${ }^{a}$ Patient died from leukopenia caused by $E$ coli sepsis with pneumonia 3 days after thiopurine treatment start. 

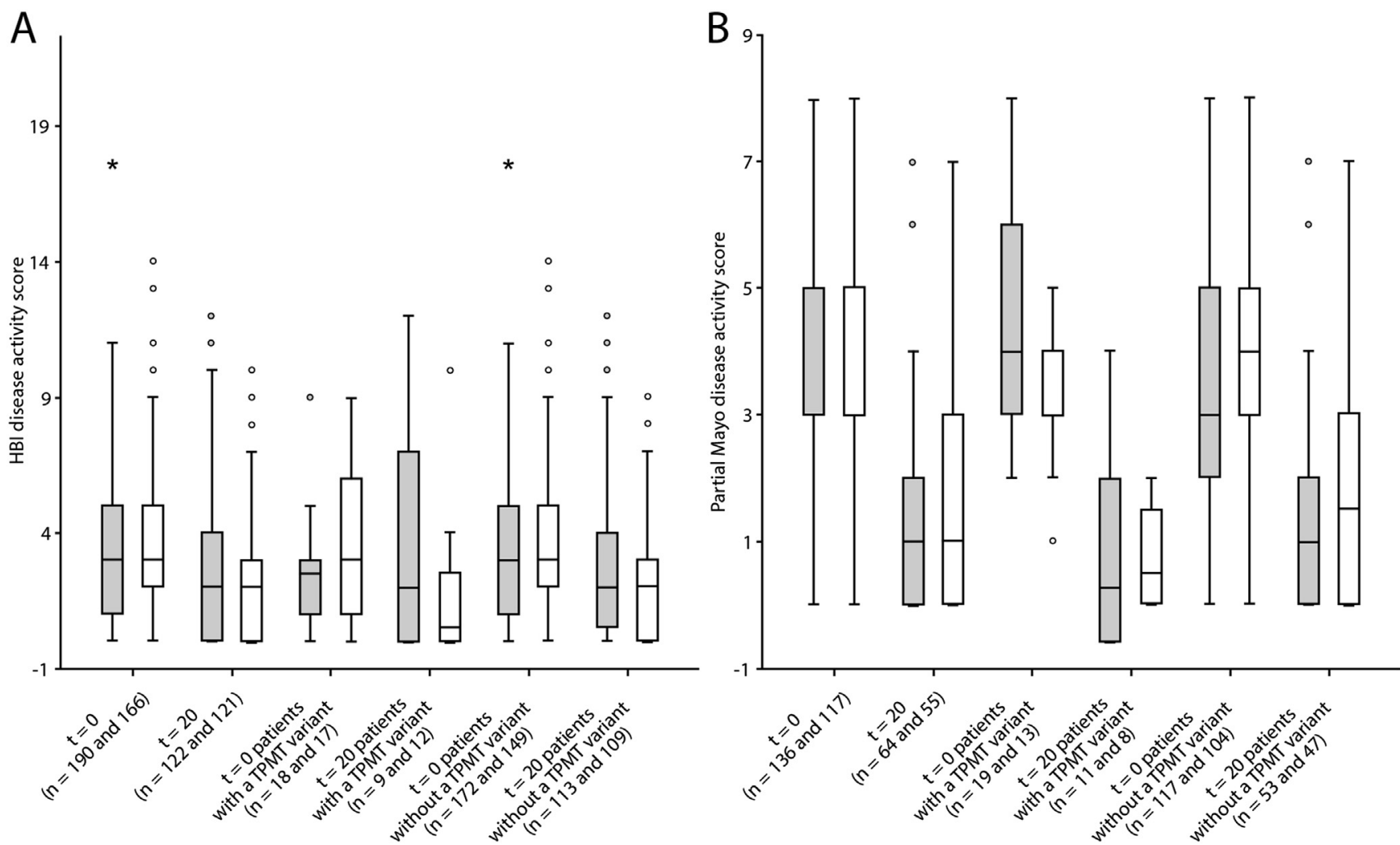

Figure 1. Box-plots for disease activity scores for patients with $(A)$ Crohn's disease (HBI) and $(B)$ ulcerative colitis (partial Mayo). Disease activity scores are shown for the intervention (grey bars) and control (white bars) groups. The HBI can range from 0 to 19 and the partial Mayo score can range from 0 to 9 , a higher score means higher disease activity. The numbers indicated for each set of boxes indicates the number of patients for the intervention and control groups, respectively. The boxes indicate the 25th to 75th percentiles and the medians are indicated by a horizontal line in the box. Whiskers indicate the 1.5 interquartile range. Open circle indicates outliers (>1.5 interquartile range), and extreme outliers (>3 interquartile range) are indicated by an asterisk. The $\mathrm{x}$-axis indicates the number of patients analyzed.

groups, indicating that both groups were equally adherent to treatment. The highest 6-methylmercaptopurine ribonucleotides concentrations were, as expected, observed in patients without a genetic TPMT variant (Figure 2B), followed by patients with a variant on standard thiopurine dose (control group); lowest levels were observed in patients treated with a reduced thiopurine dose. Six patients ( 1 in the intervention and 5 in the control group) had undetectable metabolite levels at week 8 after thiopurine initiation, suggesting noncompliance.

We also explored whether in addition to group allocation other baseline factors (co-medication, sex, age, and weight) were associated with the development of a hematologic ADR. We observed more hematologic ADRs in patients using biologics $(P=.002)$.

\section{Discussion}

The TOPIC trial, a large randomized controlled trial studying the effect of TPMT genotyping before thiopurine treatment in IBD patients, showed no significant difference in the risk of a hematologic ADR or treatment efficacy between the intervention and control groups. Post hoc analysis indicated that TPMT screening significantly reduced the risk of a hematologic ADR in the subgroup of patients with a genetic variant.

Forty percent of the patients discontinued thiopurine treatment because of adverse effects, which is relatively high compared with previous reports. ${ }^{6}$ Taking the patients with a successful re-challenge into account, we observed drop-out rates consistent with those in the literature. Despite the high discontinuation rate, we did not observe increased frequencies of hematologic ADRs in our population. ${ }^{1}$ Thus, the TOPIC trial accurately reflects the general IBD population treated with thiopurines.

We could not show a difference in the risk for occurrence of a hematologic ADR between the intervention and control groups. Other ADRs commonly observed in patients treated with thiopurines also showed comparable frequencies in the 2 groups. This latter finding was in line with expectations, because, for example, hepatotoxicity, malaise, and pancreatitis do not seem to be linked to low TPMT activity, as a meta-analysis of 1309 patients confirmed. ${ }^{20}$ The meta-analysis, however, showed a higher rate of bone marrow toxicity and overall ADR development (ie, all ADRs that required dose reduction).

A subgroup analysis in patients with a variant in the TPMT gene showed that the intervention strongly reduced 

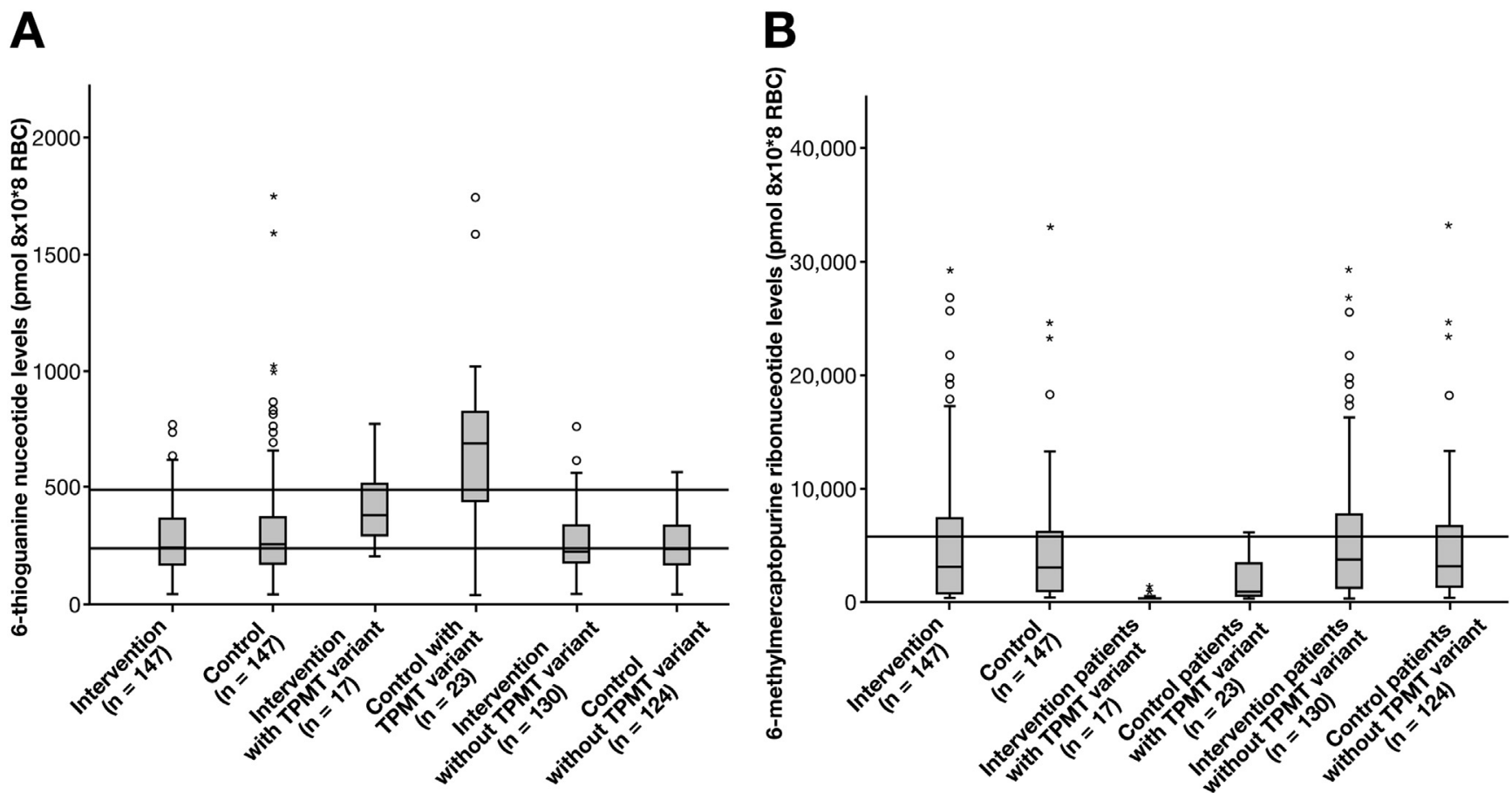

Figure 2. Box-plots for steady-state metabolite levels of $(A)$ 6-thioguanine nucleotides and $(B)$ 6-methylmercaptopurine ribonucleotides in pmol/ $8 * 10^{8}$ red blood cells measured at 8 weeks of treatment. The therapeutic range of 6 -thioguanine nucleotide metabolites (235 and $490 \mathrm{pmol} / 8 \times 10^{8}$ red blood cells) and normal range levels of 6-methylmercaptopurine ribonucleotides ( $<5700 \mathrm{pmol} / 8^{*} 10^{8}$ red blood cells) are indicated with horizontal lines in panels $A$ and $B$, respectively. The boxes indicate the 25th to 75th percentiles, and the medians are indicated by a horizontal line in the box. Whiskers indicate the 1.5 interquartile range. Open circle indicates outliers ( $>1.5$ interquartile range), and extreme outliers ( $>3$ interquartile range) are indicated by an asterisk. The number of patients analyzed are indicated on the $x$-axis. A statistically significant difference in 6-thioguanine nucleotides $(P=.004)$ and 6-methylmercaptopurine ribonucleotides $(P<.001)$ was observed between the intervention and control groups for patients carrying a TPMT variant. Similar metabolite levels were observed when excluding patients who had a dose change before 8 weeks of thiopurine therapy (Supplementary Figure 3).

hematologic ADR frequency from $22.9 \%$ to $2.6 \%$. Our data confirmed the meta-analysis including 47 mainly retrospective studies, which showed an association between decreased TPMT enzyme activity (based on genotype or phenotype) and an increased risk for leukopenia. ${ }^{3}$ In agreement with previous reports, the TOPIC trial also showed that pretreatment TPMT genotyping cannot prevent all cases of thiopurine-related hematologic ADRs, suggesting that other factors play a role in the development of these ADRs. ${ }^{21}$ The results also show that patient TPMT enzyme activity measurements would not have identified the other patients with leukopenia (1 patient of 11 with low enzyme activity developed leukopenia). It is possible that patients with leukopenia carry genetic variants in TPMT other than those analyzed..$^{15}$ However, sequencing of TPMT for 11 patients with the low TPMT enzyme activity who were negative for the 3 common TPMT variants did not show other functional mutations, indicating that sequencing the complete TPMT gene would not identify additional patients at risk for leukopenia. Several studies have suggested that genetic variants in other genes in thiopurine metabolism are associated with thiopurine-induced leukopenia. ${ }^{14,22} \mathrm{~A}$ few studies have shown that analyzing variants in 2 or more genes involved in thiopurine metabolism, including TPMT, may enhance the prediction of leukopenia, ${ }^{14,23-26}$ but further large-scale studies are warranted. Besides genetic factors, viral infections during thiopurine treatment may induce the development of leukopenia. ${ }^{21}$ Finally, comedication might make patients more susceptible to leukopenia. ${ }^{27}$ For this reason, we excluded patients receiving allopurinol as a co-medication. ${ }^{28}$ However, other commonly used treatments for IBD (eg, sulfasalazine and mesalamine) also are implicated in the development of leukopenia. ${ }^{29,30}$ And in this study, we have shown that concurrent biologics' use at treatment initiation is linked to hematological ADR development. These nongenetic factors should be taken into consideration before thiopurine initiation because they might interfere with the genotype-guided dosing. We observed a difference in biologics use at baseline between the intervention and control groups. Therefore, we also performed an analysis in patients who did not receive biologics. In this group we also showed that pretreatment genotyping resulted in a lower occurrence of hematologic ADRs. We concluded that concurrent biologics use does not interfere with the predictive ability of pretreatment TPMT genotyping for hematologic ADRs.

Importantly, similar treatment efficacy based on disease activity scores was observed in the intervention and control groups, which indicates that a reduced thiopurine dose does not result in undertreatment. The same was evident at the active metabolite level, in which patients receiving a genotype-guided thiopurine dose-reduction had a median 
steady-state 6-thioguanine nucleotide level within the therapeutic range. ${ }^{31-33}$

The results of the TOPIC study indicated that 200 patients would need to be genotyped to avoid 1 episode of a hematologic ADR (7.4\% vs 7.9\%; ie, 0.5\% risk difference). The number needed to treat to avoid one episode of a hematologic ADR would be 5 for at-risk individuals (risk difference in patients with a genetic variant is $20.3 ; 2.6 \%$ vs $22.9 \%$ ). The huge difference between the number needed to genotype and the number needed to treat can be attributed to the low frequency of the screened genetic variants in TPMT ( $10 \%)$. This nicely illustrates the difficulty in trying to use whole-population randomized studies to investigate the effectiveness of pharmacogenetic testing: the high-risk genotype constitutes a small proportion of the population (here 10\%), which makes it extremely hard to show a benefit for all patients; only a portion of the population benefits. Post hoc power analysis indeed showed that the subgroup analysis was powered sufficiently ( $80 \%$ power with 38 patients showing hematologic ADRs), but that a randomized controlled trial with 42,556 participants would be needed to show a benefit for the entire intervention group (power of $80 \%$, based on the incidence of hematologic ADRs observed in our study population).

A limitation of our study was that $12.5 \%$ of the patients were not treated according to the advised dose. However, this probably reflected the situation of genotype-guided dosing in the clinical setting. In addition, the study was performed in a nonblinded fashion. Gastroenterologists might have been able to identify patients in the intervention group receiving a reduced thiopurine dose advice $(\mathrm{n}=$ 40). However, it is not expected that these patients were treated differently; all patients were monitored regularly and because the study focused on the occurrence of (hematologic) ADRs, it was expected that gastroenterologists would be more alert to ADR development in both the intervention and control groups. Finally, the result of our post hoc analysis should be considered with caution because it was not corrected for multiple comparisons. Thus, in general, large-scale randomized controlled trials should focus their efforts specifically on the group that can be expected to benefit from genotype-guided treatment, in this specific case those patients with a TPMT variant. Strong points of our study are its prospective design and the fact that patients were included in general as well as academic hospitals, and that the decision to start thiopurine treatment was at the discretion of the gastroenterologist. This reflects the normal situation in which patients with IBD are treated.

Current guidelines for thiopurine treatment mandate regular hematologic monitoring to detect (severe) leukopenia. However, this is not a complete safeguard because leukopenia can develop suddenly. It has been suggested that pretreatment genotyping is relevant mainly for patients who are homozygous carriers of a genetic variant in $T P M T .{ }^{9} \mathrm{We}$ show that pretreatment TPMT genotyping also is relevant for patients heterozygous for a variant in TPMT. Importantly, a recent cost-effectiveness analysis $(n=333)$, in which also no differences in the ADR rate between the intervention and control groups was observed, indicated that pretreatment TPMT genotyping had a probability of $71 \%$ to be cost effective, owing to lower resource use in the intervention group. ${ }^{34}$ However, they observed a small negative effect on the quality of life. This latter was not evident from our results because treatment efficacy, as a surrogate for quality of life, was similar between groups. Pretreatment genotyping should not replace current hematologic safety monitoring, but should be considered as a (cost-effective) addition to optimize thiopurine treatment.

The results of the TOPIC trial showed no overall effect of pretreatment TPMT screening followed by personalized dosing on hematologic ADRs. However, the study, in combination with the literature, shows that pretreatment TPMT screening followed by personalized dosing reduces the risk of leukopenia in patients carrying a genetic variant in TPMT and indicates that pharmacogenetic TPMT testing should be used as standard care to individualize thiopurine treatment of IBD patients.

\section{Supplementary Material}

Note: To access the supplementary material accompanying this article, visit the online version of Gastroenterology at www.gastrojournal.org, and at http://dx.doi.org/10.1053/ j.gastro.2015.06.002.

\section{References}

1. Gisbert JP, Gomollon F. Thiopurine-induced myelotoxicity in patients with inflammatory bowel disease: a review. Am J Gastroenterol 2008;103:1783-1800.

2. Ujiie S, Sasaki T, Mizugaki M, et al. Functional characterization of 23 allelic variants of thiopurine S-methyltransferase gene (TPMT*2-*24). Pharmacogenet Genomics 2008;18:887-893.

3. Higgs JE, Payne K, Roberts C, et al. Are patients with intermediate TPMT activity at increased risk of myelosuppression when taking thiopurine medications? Pharmacogenomics 2010;11:177-188.

4. Hindorf U, Appell ML. Genotyping should be considered the primary choice for pre-treatment evaluation of thiopurine methyltransferase function. J Crohns Colitis 2012; 6:655-659.

5. Ansari A, Hassan C, Duley J, et al. Thiopurine methyltransferase activity and the use of azathioprine in inflammatory bowel disease. Aliment Pharmacol Ther 2002;16:1743-1750.

6. Jharap B, Seinen ML, de Boer NK, et al. Thiopurine therapy in inflammatory bowel disease patients: analyses of two 8-year intercept cohorts. Inflamm Bowel Dis 2010; 16:1541-1549.

7. Connell WR, Kamm MA, Ritchie JK, et al. Bone marrow toxicity caused by azathioprine in inflammatory bowel disease: 27 years of experience. Gut 1993;34:1081-1085.

8. Roblin X, Oussalah A, Chevaux JB, et al. Use of thiopurine testing in the management of inflammatory bowel diseases in clinical practice: a worldwide survey of experts. Inflamm Bowel Dis 2011;17:2480-2487. 
9. Newman WG, Payne K, Tricker K, et al. A pragmatic randomized controlled trial of thiopurine methyltransferase genotyping prior to azathioprine treatment: the TARGET study. Pharmacogenomics 2011;12:815-826.

10. Fargher EA, Tricker K, Newman W, et al. Current use of pharmacogenetic testing: a national survey of thiopurine methyltransferase testing prior to azathioprine prescription. J Clin Pharm Ther 2007;32:187-195.

11. Pirmohamed M, Burnside G, Eriksson N, et al. A randomized trial of genotype-guided dosing of warfarin. N Engl J Med 2013;369:2294-2303.

12. Mallal S, Phillips E, Carosi G, et al. HLA-B*5701 screening for hypersensitivity to abacavir. N Engl J Med 2008;358:568-579.

13. Verhoef $\mathrm{TI}$, Ragia $\mathrm{G}$, de Boer $\mathrm{A}$, et al. A randomized trial of genotype-guided dosing of acenocoumarol and phenprocoumon. N Engl J Med 2013;369:2304-2312.

14. Derijks LJ, Wong DR. Pharmacogenetics of thiopurines in inflammatory bowel disease. Curr Pharm Des 2010; 16:145-154.

15. Schaeffeler E, Fischer C, Brockmeier D, et al. Comprehensive analysis of thiopurine S-methyltransferase phenotype-genotype correlation in a large population of German-Caucasians and identification of novel TPMT variants. Pharmacogenetics 2004;14:407-417.

16. Swen JJ, Nijenhuis M, de Boer A, et al. Pharmacogenetics: from bench to byte-an update of guidelines. Clin Pharmacol Ther 2011;89:662-673.

17. Ford L, Graham V, Berg J. Whole-blood thiopurine Smethyltransferase activity with genotype concordance: a new, simplified phenotyping assay. Ann Clin Biochem 2006;43:354-360.

18. Lennard L, Singleton HJ. High-performance liquid chromatographic assay of human red blood cell thiopurine methyltransferase activity. J Chromatogr B Biomed Appl 1994;661:25-33.

19. Yates CR, Krynetski EY, Loennechen T, et al. Molecular diagnosis of thiopurine S-methyltransferase deficiency: genetic basis for azathioprine and mercaptopurine intolerance. Ann Intern Med 1997;126:608-614.

20. Dong XW, Zheng Q, Zhu MM, et al. Thiopurine S-methyltransferase polymorphisms and thiopurine toxicity in treatment of inflammatory bowel disease. World J Gastroenterol 2010;16:3187-3195.

21. Colombel JF, Ferrari N, Debuysere H, et al. Genotypic analysis of thiopurine S-methyltransferase in patients with Crohn's disease and severe myelosuppression during azathioprine therapy. Gastroenterology 2000;118: 1025-1030.

22. Yang SK, Hong M, Baek J, et al. A common missense variant in NUDT15 confers susceptibility to thiopurineinduced leukopenia. Nat Genet 2014;46:1017-1020.

23. Palmieri O, Latiano A, Bossa F, et al. Sequential evaluation of thiopurine methyltransferase, inosine triphosphate pyrophosphatase, and HPRT1 genes polymorphisms to explain thiopurines' toxicity and efficacy. Aliment Pharmacol Ther 2007;26:737-745.

24. Zabala-Fernandez W, Barreiro-de Acosta M, Echarri A, et al. A pharmacogenetics study of TPMT and ITPA genes detects a relationship with side effects and clinical response in patients with inflammatory bowel disease receiving azathioprine. J Gastrointest Liver Dis 2011; 20:247-253.

25. Uchiyama K, Nakamura M, Kubota T, et al. Thiopurine S-methyltransferase and inosine triphosphate pyrophosphohydrolase genes in Japanese patients with inflammatory bowel disease in whom adverse drug reactions were induced by azathioprine/6-mercaptopurine treatment. J Gastroenterol 2009;44:197-203.

26. Zelinkova Z, Derijks LJ, Stokkers PC, et al. Inosine triphosphate pyrophosphatase and thiopurine s-methyltransferase genotypes relationship to azathioprineinduced myelosuppression. Clin Gastroenterol Hepatol 2006;4:44-49.

27. van Asseldonk DP, Kanis BM, de Boer NK, van Bodegraven AA, et al. Leukopenia due to parvovirus B19 in a Crohn's disease patient using azathioprine. Digestion 2009;79:211-214.

28. Venkat Raman G, Sharman VL, Lee HA. Azathioprine and allopurinol: a potentially dangerous combination. J Intern Med 1990;228:69-71.

29. Nguyen TM, Le Gall C, Lachaux A, et al. High thiopurine metabolite concentrations associated with lymphopenia in inflammatory bowel disease (IBD) pediatric patients receiving aminosalicylates combined with azathioprine. Int J Clin Pharmacol Ther 2010;48:275-281.

30. Xin H, Fischer C, Schwab M, et al. Effects of aminosalicylates on thiopurine S-methyltransferase activity: an ex vivo study in patients with inflammatory bowel disease. Aliment Pharmacol Ther 2005;21:1105-1109.

31. Cuffari C, Hunt S, Bayless T. Utilisation of erythrocyte 6thioguanine metabolite levels to optimise azathioprine therapy in patients with inflammatory bowel disease. Gut 2001;48:642-646.

32. Cuffari C, Theoret Y, Latour S, et al. 6-Mercaptopurine metabolism in Crohn's disease: correlation with efficacy and toxicity. Gut 1996;39:401-406.

33. Dubinsky MC, Lamothe S, Yang HY, et al. Pharmacogenomics and metabolite measurement for 6-mercaptopurine therapy in inflammatory bowel disease. Gastroenterology 2000;118:705-713.

34. Thompson AJ, Newman WG, Elliott RA, et al. The costeffectiveness of a pharmacogenetic test: a trial-based evaluation of TPMT genotyping for azathioprine. Value Health 2014;17:22-33.

\section{Author names in bold designate shared co-first authorship.}

Received February 6, 2015. Accepted June 3, 2015.

\section{Reprint requests}

Address requests for reprints to: Marieke Coenen, PhD, Department of Human Genetics (855), Radboud Institute for Health Sciences, Radboud university medical center, PO Box 9101, 6500HB Nijmegen, The Netherlands. e-mail: marieke.coenen@radboudumc.nl; fax: (31) (0)24-3668752.

\section{Acknowledgments}

The authors thank the patients for their participation in the study. The authors thank A. Marlies Naber, BASc, and Johanne M. Groothuismink, BASc, from the Department of Human Genetics, Radboud university medical center (Nijmegen, The Netherlands); Mariëlle Maas, Miet Fiddelaers, Milevis Reitsma, Leonie Peters, and Jean Cilissen from the Department of Clinical Pharmacy and Toxicology, Orbis Medical Center (Sittard-Geleen, The Netherlands) for technical assistance; and Debbie Heinen, MSc, Marjolein M. J. van Donkelaar, MSc, Freshteh Golestani, Marlies E. de Vos, MSc, J. G. Angelien 
M. Heister, BASc, Doménique M. W. Nijsten, MSc, Mascha M. V. A. P. Schijvenaars, BASc, and Martine E. C. Cranen, MSc from the Department of Human Genetics, Radboud university medical center (Nijmegen, The Netherlands) for their support in data management.

The TOPIC recruitment team was responsible for patient recruitment and collection of clinical data. Compensation was given to the members of the recruitment team for additional biochemical measurements and examinations that had to be performed for the TOPIC study. TOPIC recruitment team collaborators are as follows: from the Department of Gastroenterology, Academisch Ziekenhuis Maastricht, Maastricht, The Netherlands: A. A. M. Masclee, MD, PhD; M. Pierik, MD, PhD; W. Mares, MD; and W. Hameeteman, MD, PhD; from the Department of Gastroenterology, Rijnstate Ziekenhuis Arnhem, Arnhem, The Netherlands: P. J. Wahab, MD, PhD; and $\mathrm{H}$. Seinen, MD, PhD; from the Department of Gastroenterology, Amphia Ziekenhuis, Breda, The Netherlands: M. C. M. Rijk, MD, PhD; and I. M. Harkema, MD; from the Department of Gastroenterology, Atrium Medisch Centrum, Heerlen, The Netherlands: M. de Bièvre, MD; L. Oostenbrug, MD, PhD; C. M. Bakker, MD, PhD; M. Aquarius, MD; C. van Deursen, MD, PhD; A. B. van Nunen, MD, PhD; J. G. Goedhard, MD, PhD; and M. Hamacher, MD; from the Department of Gastroenterology, Bernhoven Hospital, Oss, The Netherlands: I. A. M. Gisbertz, MD, PhD; and B. J. Brenninkmeijer, MD, PhD; from the Department of Gastroenterology, Canisius Wilhelmina Ziekenhuis, Nijmegen, The Netherlands: A. C. I. T. L. Tan, MD, PhD; M. N. AparicioPagés, MD, PhD, and E. M. Witteman, MD, PhD; from the Department of Gastroenterology, Diakonessenhuis, Utrecht, The Netherlands: S. A. C. van Tuyl, MD; and R. Breumelhof, MD, PhD; from the Department of Gastroenterology, Catharina Ziekenhuis, Eindhoven, The Netherlands; A. Stronkhorst, MD, PhD; L. P. L. Gilissen, MD, PhD; and E. J. Schoon, MD, PhD; from the Department of Gastroenterology, Elkerliek Ziekenhuis, Helmond, The Netherlands: J. W. M. Tjhie-Wensing, MD; and A. Temmerman, MD; from the HagaZiekenhuis, 's-Gravenhage, The Netherlands: J. J. Nicolaï, MD, PhD; from the Department of Gastroenterology, Gelderse Vallei Hospital, Ede, The Netherlands: J. D. van Bergeijk, MD, PhD; D. J. Bac, MD, PhD; B. J. M. Witteman, MD, PhD; N. Mahmmod, MD; J. J. Uil, MD, PhD; and H. Akol, MD, PhD; from the Department of Gastroenterology, Ikazia Hospital, Rotterdam, The Netherlands: R. J. T. Ouwendijk, MD, PhD; from the Department of Gastroenterology, Jeroen Bosch Hospital, 's-Hertogenbosch, The Netherlands: I. P. van Munster, MD, PhD; M. Pennings, MD; A. M. P. De Schryver, MD, PhD; T. J. M. van Ditzhuijsen, MD, PhD; R. C. H. Scheffer, MD, PhD; T. E. H. Römkens, MD; and D. L. Schipper, MD, PhD; from the Department of Gastroenterology, Laurentius Hospital, Roermond, The Netherlands: P. J. Bus, MD; from the Department of Gastroenterology, Máxima Medisch Centrum, Eindhoven-Veldhoven, The Netherlands: J. W. A. Straathof, MD, PhD; M. L. Verhulst, MD, PhD; P. J. Boekema, MD, PhD; J. T. Kamphuis, MD; H. J. van Wijk, MD, PhD; and J. M. J. L. Salemans, MD, PhD; from the Department of Gastroenterology, Meander MC, Amersfoort,
The Netherlands: J. R. Vermeijden, MD; from the Department of Gastroenterology, MC Haaglanden, Den Haag, The Netherlands: S. D. J. van der Werf, MD, PhD; and R. J. Verburg, MD, PhD; from the Department of Gastroenterology, Medisch Centrum Leeuwarden, Leeuwarden, The Netherlands: P. Spoelstra, MD, PhD; J. M. L. de Vree, MD, PhD; K. van der Linde, MD, PhD; H. J. A. Jebbink, MD, PhD; M. Jansen; and H. Holwerda; from the Department of Gastroenterology, Medisch Spectrum Twente, Enschede, The Netherlands: N. van Bentem, MD; J. J. Kolkman, MD, PhD; M. G. V. M. Russel, MD, PhD; G. H. van Olffen, MD; M. J. Kerbert-Dreteler, MD; M. Bargeman, MD, PhD; J. M. Götz, MD, PhD; and R. Schröder, MD; from the Department of Gastroenterology, Onze Lieve Vrouwe Gasthuis, Amsterdam, The Netherlands: J. M. Jansen, MD; from the Department of Gastroenterology, Orbis Medisch Centrum, Sittard-Geleen, The Netherlands: L. P. Bos, MD, PhD; L. G. J. B. Engels, MD, PhD; M. J. L. Romberg-Camps, $\mathrm{MD}$; and E. T. P. Keulen, MD, PhD; from the Department of Gastroenterology, Radboud university medical center, Nijmegen, The Netherlands: A. A. J. van Esch, MD; J. P. H. Drenth, MD, PhD; M. C. A. van Kouwen, MD, PhD; G. J. A. Wanten, MD, PhD; T. J. Bisseling, MD, PhD; T. E. H. Römkens, MD; and M. W. J. van Vugt; from the Department of Gastroenterology, Slingeland Hospital, Doetinchem, The Netherlands: P. C. van de Meeberg, MD, PhD; and S. J. van den Hazel, MD, PhD; from the Department of Gastroenterology, St Elisabeth Ziekenhuis, Tilburg, The Netherlands: W. N. H. M. Stuifbergen, MD, PhD; M. J. A. L. Grubben, MD PhD; U. de Wit, MD, PhD; G. A. H. Dodemont, MD, PhD; and R. F. Eichhorn, $\mathrm{MD}$; from the Department of Gastroenterology, Tergooiziekenhuizen, Blaricum-Hilversum, The Netherlands: J. M. H. van den Brande, MD, PhD A. H. J. Naber, MD, PhD; E. J. van Soest, MD, PhD; and P. J. Kingma, MD, $\mathrm{PhD}$; from the Department of Gastroenterology, TweeSteden Ziekenhuis, Tilburg, The Netherlands: N. C. Talstra, MD; K. F. Bruin, MD, PhD; and F. H. J. Wolfhagen, MD, PhD; from the Department of Gastroenterology, University Medical Centre Leiden, Leiden, The Netherlands: D. W. Hommes, MD, PhD P. P. J. van der Veek, MD, PhD; J. C. A. Hardwick, MD, PhD; R. J. Stuyt, $\mathrm{MD}, \mathrm{PhD}$; and H. H. Fidder, MD; Department of Gastroenterology, University Medical Centre Utrecht, Utrecht, The Netherlands: B. Oldenburg, MD, PhD and from the Department of Gastroenterology, Ziekenhuisgroep Twente, Hengelo, The Netherlands: T. G. Tan, MD.

\section{Conflicts of interest}

The authors disclose no conflicts.

\section{Funding}

The study was funded by The Netherlands Organization for Health Research and Development (94507606) and the participating institutes. The funding organization had no role in the design or conduct of the study; collection, management, analysis, or interpretation of the data; preparation, review, or approval of the manuscript; or the decision to submit the manuscript for publication. 


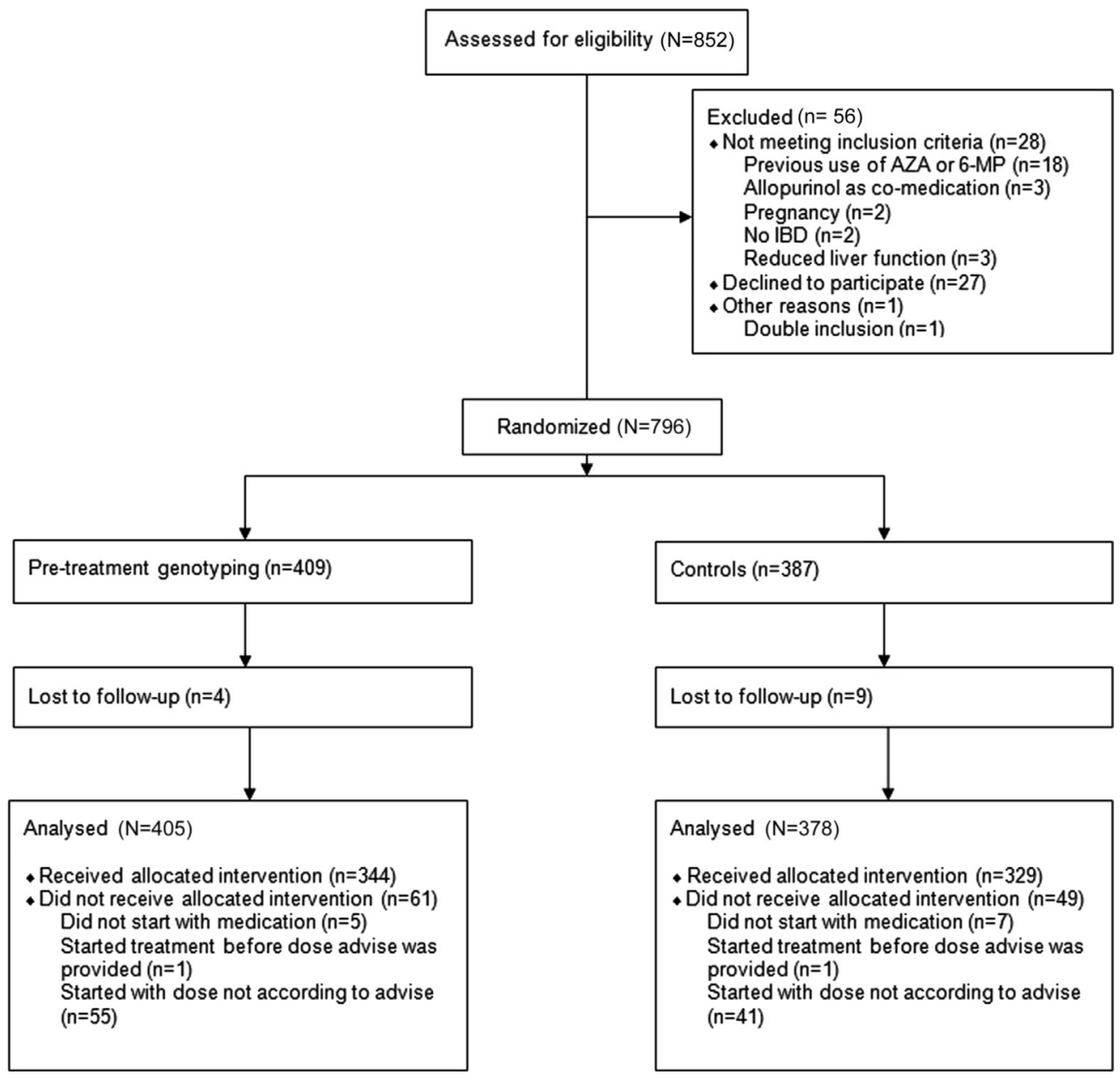

Supplementary

Figure 1. Study design of the TOPIC trial. AZA, azathioprine; 6-MP, 6mercaptopurine. 

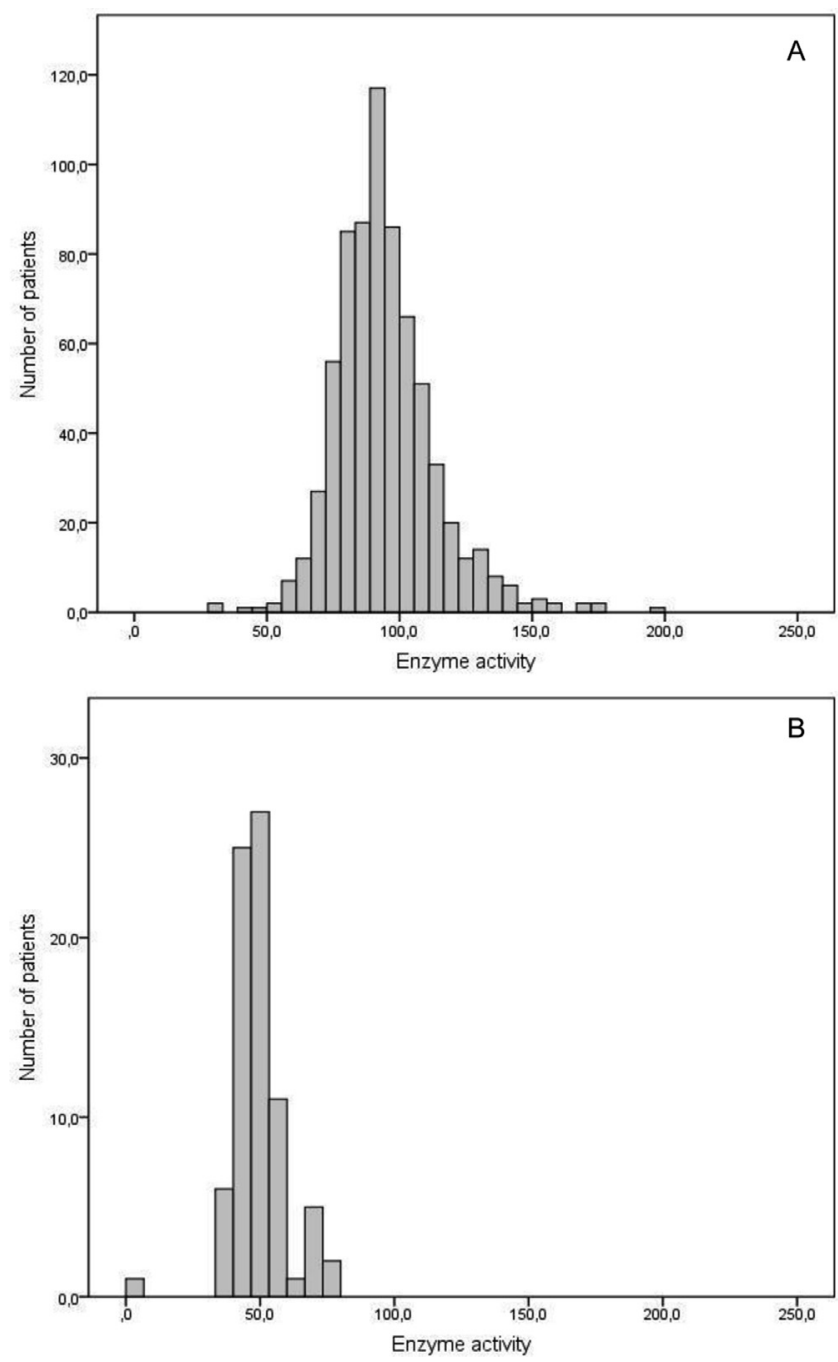

Supplementary Figure 2. TPMT enzyme activity distribution in the study population. Overview of the enzyme activity $(\mathrm{mg} /$ mmol hemoglobin per hour) distribution in patients $(A)$ without a genetic variant $(n=705)$ and $(B)$ with a genetic variant $(n=$ 78) in the TPMT gene. Each bar represents 5 units of the scale (eg, 0-5, >5-10). Patients not carrying a TPMT variant had a mean enzyme activity for 6-methylguanine of $94.5 \pm 19.0 \mathrm{mg} /$ $\mathrm{mmol}$ hemoglobin per hour, and in heterozygous patients the mean TPMT enzyme activity of 6-methylguanine was $49.4 \pm$ $10.7 \mathrm{mg} / \mathrm{mmol}$ hemoglobin per hour. The patient homozygous for TPMT $3 A$ had an enzyme activity of $0.50 \mathrm{mg} \mathrm{6}$ methylguanine/mmol hemoglobin per hour before thiopurine therapy.
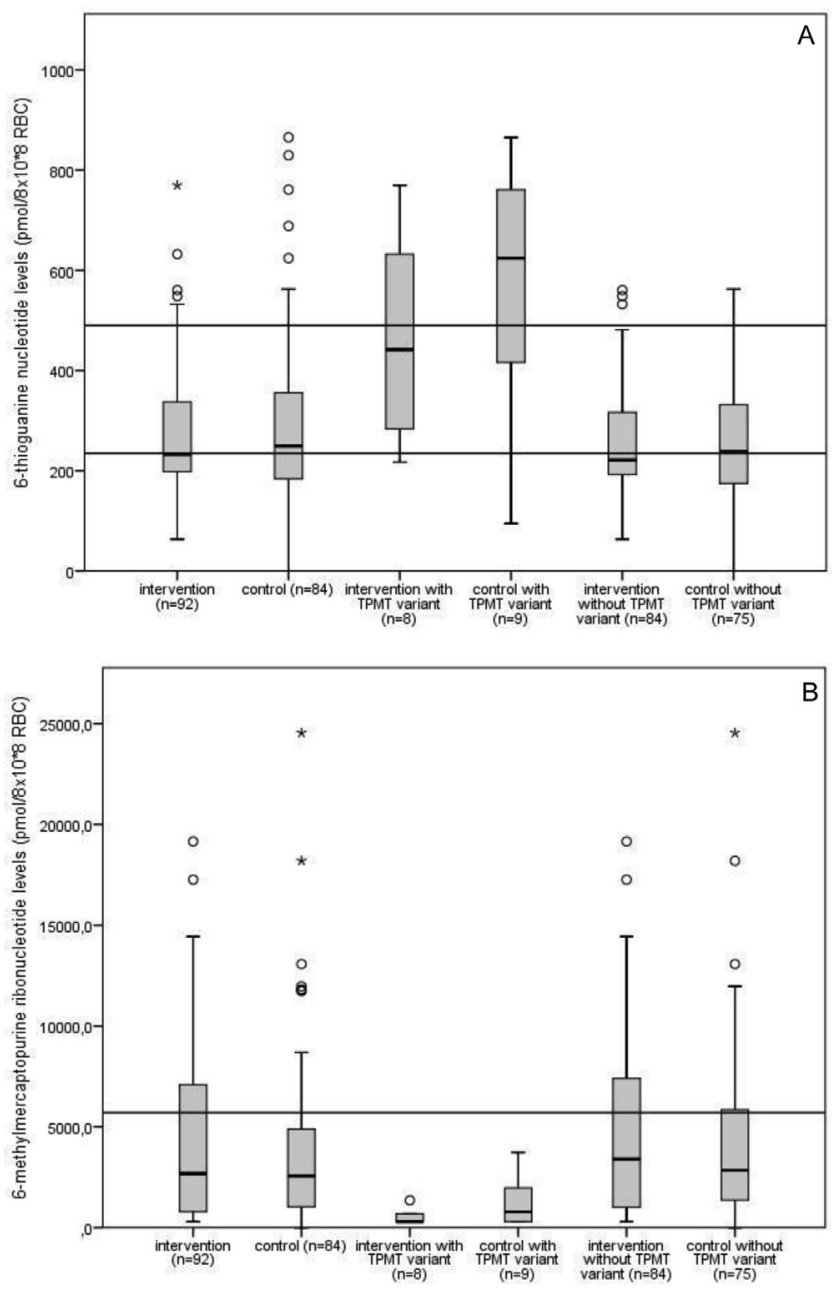

Supplementary Figure 3. Box-plots for steady-state metabolite levels 6-thioguanine nucleotides (6-TGN) and 6-methylmercaptopurine ribonucleotides (6-MMPR) after exclusion of patients who received a dose change before 8 weeks of treatment start. Box-plots for steady-state metabolite levels of $(A) 6-$ TGN and $(B) 6-\mathrm{MMPR}$ in $\mathrm{pmol} / 8^{*} 10^{8} \mathrm{red}$ blood cells after exclusion of patients who received a dose change before 8 weeks of treatment start. Metabolite levels were measured at 8 weeks of treatment. The therapeutic range of 6-TGN metabolites $\left(235\right.$ and $490 \mathrm{pmol} / 8 \times 10^{8} \mathrm{red}$ blood cells) and normal range levels of 6 -MMPR $(<5700$ $\mathrm{pmol} / 8^{*} 10^{8}$ red blood cells) are indicated with horizontal lines in panels $A$ and $B$, respectively. The boxes indicate the 25th to 75 th percentile and the medians are indicated by a horizontal line in the box. Whiskers indicate 1.5 interquartile range. Open circle indicates outliers (>1.5 interquartile range) and extreme outliers ( $>3$ interquartile range) are indicated by an asterisk. The numbers on the $\mathrm{x}$-axis indicate the number of patients analyzed. 
Supplementary Table 1. Overview of the Primers Used for Sequencing of the Protein-Coding Part of the TPMT Gene

\begin{tabular}{lll}
\hline Exon & \multicolumn{1}{c}{ Forward primer } & \multicolumn{1}{c}{ Reverse primer } \\
\hline 3 & AGGTTTCATTAGTTCATCAAT & TITTGATAGAACATTTCTCTATTGT \\
4 & TGAATGAAAATGTTCACCTACC & TTCAAAACTCAATCCAGAAAGA \\
5 & TCTTTGAACCCTATGAACCTGA & AAAACTTTGTGGGGATATGGA \\
6 & GCCCTCTTCCTTGACTATT & GAGGAAGACACCTCCACTCC \\
7 & TGTTGAAGTACCAGCATGCAC & TTCCAAACATAATAACCTATTCAAAC \\
8 & CGAAAGTAACTTCTGGCTTC & GGCAACTGGTAAAAGAAAA \\
9 & TGAGAAGAACATGCCACATCA & GCCAGGCCCAAAAGATTA \\
10 & CACCCAGCCAATTTGAGTA & ACAGGTAACACATGCTGATTGG
\end{tabular}

NOTE. Polymerase chain reaction was performed on $10 \mathrm{ng}$ DNA using AmpliTaq Gold 360 mastermix (Life Technologies). The annealing temperature was $56^{\circ} \mathrm{C}$ for all exons. Sequencing was performed using Sanger technology.

Supplementary Table 2. Overview of Baseline IBD Classification in the Study Population

\begin{tabular}{|c|c|c|c|c|c|c|}
\hline \multirow[b]{2}{*}{ Disease $^{a}$} & \multicolumn{2}{|c|}{ Total population } & \multicolumn{2}{|c|}{ Intervention group } & \multicolumn{2}{|c|}{ Control group } \\
\hline & CD & UC & CD & UC & CD & UC \\
\hline Total, n (\%) & $476(61.0 \%)$ & $300(38.5 \%)$ & $245(60.5 \%)$ & 157 (38.8\%) & $231(61.1 \%)$ & $143(37.8 \%)$ \\
\hline Presence of fistula & $43(9.3 \%)^{b}$ & & $19(7.8 \%)^{c}$ & & $24(10.5 \%)^{d}$ & \\
\hline Localization CD known & $\mathrm{n}=466$ & & $\mathrm{n}=239$ & & $\mathrm{n}=227$ & \\
\hline Ileum (L1) & $159(34.1 \%)$ & & $88(36.3 \%)$ & & $71(31.3 \%)$ & \\
\hline Colon (L2) & $113(24.2 \%)$ & & $52(21.8 \%)$ & & $61(26.9 \%)$ & \\
\hline lleum and colon (L3) & $194(41.6 \%)$ & & $99(41.4 \%)$ & & $95(41.9 \%)$ & \\
\hline Localization UC known & & $n=293$ & & $\mathrm{n}=152$ & & $\mathrm{n}=141$ \\
\hline Proctitis ulcerosa (E1) & & $38(13.0 \%)$ & & $23(15.1 \%)$ & & $15(10.6 \%)$ \\
\hline Left-sided colitis (E2) & & $121(41.3 \%)$ & & $67(44.1 \%)$ & & $54(14.3 \%)$ \\
\hline Pancolitis (E3) & & $134(45.7 \%)$ & & $62(40.8 \%)$ & & $72(19.0 \%)$ \\
\hline
\end{tabular}

NOTE. L indicates localization of Crohn's disease and E indicates extent of ulcerative colitis, both according to the Montreal classification.

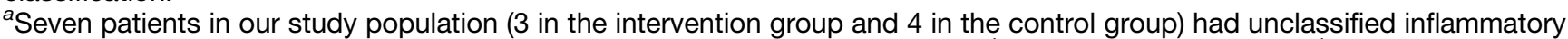
bowel disease. The total number of patients for whom fistulas were assessed: ${ }^{b} n=468,{ }^{c} n=243$, and ${ }^{d} n=225$. 
Supplementary Table 3. Corticosteroid Use in the Intervention and Control Groups

Intervention group $(\mathrm{N}=405)$

Control group $(\mathrm{N}=378)$

Steroid use at $\mathrm{t}=0, \mathrm{n}(\%)$

All steroids, systemic and local

Systemic steroids

328 (81.0)

321 (79.3)

74 (18.3)

56 (13.8)

171 (42.2)

160 (39.5)

348 (85.9)

340 (84.0)

$0.71(0.39)$

$0.66(0.40)$
$306(81.0)$

293 (77.5)

67 (17.7)

57 (15.1)

$170(45.0)$

156 (41.3)

322 (85.2)

309 (81.7)

$0.71(0.39)$

$0.66(0.40)$

${ }^{a}$ Duration was calculated as the percentage of the study period. Comparisons in steroid use between the intervention and control groups, using the $X^{2}$ test or the Mann-Whitney $U$ test for the duration of steroid use, showed no statistically significant differences. 


\begin{tabular}{|c|c|c|c|c|c|c|c|c|c|c|c|c|c|c|}
\hline & \multicolumn{2}{|l|}{ Total } & \multicolumn{6}{|c|}{ Intervention } & \multicolumn{6}{|c|}{ Control } \\
\hline & Total $^{a}$ & $\mathrm{~N}$ & $\begin{array}{l}\text { Intervention } \\
\text { total }\end{array}$ & $\mathrm{N}$ & $\begin{array}{l}\text { With a TPMT } \\
\text { variant }^{a}\end{array}$ & $\mathrm{n}$ & $\begin{array}{c}\text { Without a TPMT } \\
\text { variant }\end{array}$ & $\mathrm{n}$ & $\begin{array}{l}\text { Control } \\
\text { total }\end{array}$ & $\mathrm{N}$ & $\begin{array}{l}\text { With a TPMT } \\
\text { variant }\end{array}$ & $\mathrm{n}$ & $\begin{array}{c}\text { Without a TPMT } \\
\text { variant }\end{array}$ & $\mathrm{n}$ \\
\hline \multicolumn{15}{|c|}{$\begin{array}{l}\text { Dose start, } \mathrm{mg} / \mathrm{kg} \\
\text { mean (minimum-maximum) }\end{array}$} \\
\hline Azathioprine & $2.0(0-3.1)$ & 506 & $2.1(0-2.7)$ & 258 & $1.1(0-1.4)$ & 27 & $2.2(0-2.7)$ & 231 & $2.2(0-3.1)$ & 248 & $2.1(0-2.4)$ & 22 & $2.2(0-3.1)$ & 226 \\
\hline 6-Mercaptopurine & $1.1(0-2.2)$ & 277 & $1.2(0-2.2)$ & 147 & $0.6(0.5-0.8)$ & 13 & $1.2(0-2.2)$ & 134 & $1.2(0-2.0)$ & 130 & $1.2(0-1.5)$ & 14 & $1.2(0.6-2.0)$ & 116 \\
\hline \multicolumn{15}{|c|}{$\begin{array}{l}\text { Dose week } 20, \mathrm{mg} / \mathrm{kg} \\
\text { mean (minimum-maximum) }\end{array}$} \\
\hline Azathioprine & $2.1(0.5-3.1)$ & 323 & $2.1(0.5-2.7)$ & 162 & $1.0(0.5-1.5)$ & 15 & $2.1(0.5-2.7)$ & 147 & $2.2(0.6-3.1)$ & 161 & $2.1(0.7-2.4)$ & 18 & $2.2(0.6-3.1)$ & 143 \\
\hline 6-Mercaptopurine & $1.0(0.3-1.5)$ & 208 & $1.1(0.3-1.5)$ & 104 & $0.6(0.3-1.0)$ & 9 & $1.1(0.4-1.5)$ & 95 & $1.1(0.4-1.5)$ & 104 & $1.1(0.8-1.3)$ & 8 & $1.1(0.4-1.5)$ & 96 \\
\hline Treatment stop, n (\%) & $313(40.0)$ & 783 & $170(42.0)$ & 405 & $19(47.5)$ & 40 & $151(41.4)$ & 365 & $143(37.8)$ & 378 & $9(25)$ & 36 & 134 (39.2) & 342 \\
\hline Treatment restart, n (\%) & $117(14.9)$ & 783 & $57(14.1)$ & 405 & $4(10.0)$ & 40 & $53(14.5)$ & 365 & 60 (15.9) & 378 & $1(2.8)$ & 36 & 59 (17.3) & 342 \\
\hline Dose change, n (\%) & $235(30.0)$ & 783 & $118(29.1)$ & 405 & $6(15.0)$ & 40 & $112(30.7)$ & 365 & $117(31.0)$ & 378 & 7 (19.4) & 36 & $110(32.2)$ & 342 \\
\hline $\begin{array}{l}\text { Thiopurine treatment } \\
\text { week } 20, \mathrm{n}(\%)\end{array}$ & $531(67.8)$ & 783 & $266(65.7)$ & 405 & $24(60)$ & 40 & $242(66.3)$ & 365 & $262(69.3)$ & 378 & $26(72.2)$ & 36 & 239 (70.0) & 342 \\
\hline $\begin{array}{l}\text { Days thiopurine use, } \\
\text { mean }(\mathrm{SD})^{b}\end{array}$ & $0.59(0.41)$ & 783 & $0.59(0.41)$ & 405 & $0.57(0.43)$ & 40 & $0.59(0.41)$ & 365 & $0.59(0.41)$ & 378 & $0.62(0.41)$ & 36 & $0.59(0.41)$ & 342 \\
\hline
\end{tabular}

${ }^{a}$ Patients not starting treatment were included in the azathioprine or 6-mercaptopurine group depending on the treatment that should be initiated.

${ }^{b}$ Days of thiopurine use were calculated as a percentage of the study period. Treatment stop describes the patients who discontinued treatment during the follow-up period, this includes patients who subsequently restarted treatment. Comparisons between the intervention and control groups, using the $X^{2}$ test or the MannWhitney $U$ test for dose and days of thiopurine use, showed statistically significant differences for 6 -mercaptopurine dose at treatment initiation between the intervention and control groups $(P=.045)$ and for azathioprine dose at week $20(P=.014)$. Azathioprine and 6 -mercaptopurine doses were both significantly different between the intervention and control groups for the patients with a genetic variant in TPMT at treatment start $(P<.004)$ and at 20 weeks $(P \leq .001)$. 
Supplementary Table 5. Patient Enrollment per Center and Number of Patients Starting With a Dose Not According to the Provided Advice

\begin{tabular}{|c|c|c|c|}
\hline Center number & Total number of patients included & Patients carrying a variant in $\mathrm{TPMT}^{a}$ & Protocol violations $^{a}$ \\
\hline 1 & $48(6.1)$ & $5(10.4)$ & $6(12.5)$ \\
\hline 2 & $10(1.3)$ & $0(0)$ & $1(10)$ \\
\hline 3 & $34(4.3)$ & $4(11.8)$ & $4(11.8)$ \\
\hline 4 & $14(1.8)$ & $1(7.1)$ & $1(7.1)$ \\
\hline 5 & 33 (4.2) & 6 (18.2) & $8(24.2)$ \\
\hline 6 & $20(2.6)$ & 1 (5) & 1 (1.4) \\
\hline 7 & $38(4.9)$ & $4(10.5)$ & $8(4.75)$ \\
\hline 8 & $19(2.4)$ & $2(10.5)$ & $3(15.8)$ \\
\hline 9 & $54(6.9)$ & $5(9.3)$ & 17 (31.5) \\
\hline 10 & $5(0.6)$ & $1(20)$ & $1(20)$ \\
\hline 11 & $28(3.6)$ & $0(0)$ & $0(0)$ \\
\hline 12 & $59(7.5)$ & $7(11.9)$ & $8(13.6)$ \\
\hline 13 & 84 (10.7) & 9 (10.7) & 7 (8.3) \\
\hline 14 & $31(4.0)$ & $5(16.1)$ & $4(12.9)$ \\
\hline 15 & $51(6.5)$ & $8(15.7)$ & $18(35.3)$ \\
\hline 16 & $10(1.3)$ & $1(10)$ & $0(0)$ \\
\hline 17 & $26(3.3)$ & $2(7.7)$ & $1(3.8)$ \\
\hline 18 & $29(3.7)$ & 3 (10.3) & $3(10.3)$ \\
\hline 19 & $48(6.1)$ & $2(4.2)$ & $2(4.2)$ \\
\hline 20 & $2(0.3)$ & $0(0)$ & $0(0)$ \\
\hline 21 & $40(5.1)$ & $2(5.0)$ & $2(5.0)$ \\
\hline 22 & $19(2.4)$ & 2 (10.5) & $1(5.3)$ \\
\hline 23 & $47(6.0)$ & $4(8.5)$ & 5 (10.6) \\
\hline 24 & $1(0.1)$ & $0(0)$ & $0(0)$ \\
\hline 25 & $4(0.5)$ & $0(0)$ & $2(50)$ \\
\hline 26 & $1(0.1)$ & $1(100)$ & $0(0)$ \\
\hline 27 & $18(2.3)$ & 2 (11.1) & 6 (33.3) \\
\hline 28 & $4(0.5)$ & $0(0)$ & $1(25)$ \\
\hline 29 & $3(0.4)$ & $0(0)$ & $0(0)$ \\
\hline 30 & $3(0.4)$ & 1 (33.3) & $0(0)$ \\
\hline Total & 783 (100) & 78 (10.0) & $110(14.0)$ \\
\hline
\end{tabular}

NOTE. Data shown are n (\%).

${ }^{a}$ Percentage of the number of patients included at a particular center. 


\begin{tabular}{|c|c|c|c|c|c|c|c|c|c|c|c|c|}
\hline & \multicolumn{6}{|c|}{ Intervention } & \multicolumn{6}{|c|}{ Control } \\
\hline & Total & $\begin{array}{c}\mathrm{n} \\
\text { total }\end{array}$ & TMPT variant & $\begin{array}{c}\mathrm{n} \\
\text { total }\end{array}$ & No variant & $\begin{array}{c}\mathrm{n} \\
\text { total }\end{array}$ & Total & $\mathrm{n}$ total & TMPT variant & $\begin{array}{c}\mathrm{n} \\
\text { total }\end{array}$ & No variant & $\begin{array}{c}\mathrm{n} \\
\text { total }\end{array}$ \\
\hline Remission ${ }^{a}$ & 55 (69.6\%) & 79 & 9 (75.0\%) & 12 & $46(68.7 \%)$ & 67 & 58 (67.4\%) & 86 & 9 (90.0\%) & 10 & 49 (64.5\%) & 76 \\
\hline $\mathrm{HBI}$ & $19(61.3 \%)$ & 31 & $1(50.0 \%)$ & 2 & $18(62.1 \%)$ & 29 & $31(75.6 \%)$ & 41 & $4(80.0 \%)$ & 5 & 27 (75.0\%) & 36 \\
\hline Partial Mayo & $36(75.0 \%)$ & 48 & $8(80.0 \%)$ & 10 & $28(73.7 \%)$ & 38 & $27(60.0 \%)$ & 45 & $5(100.0 \%)$ & 5 & $22(55.0 \%)$ & 40 \\
\hline \multicolumn{13}{|l|}{$\mathrm{ESR}^{b}$ all patients } \\
\hline Absolute change & $2.0(-83.0$ to 90.0$)$ & 208 & $8.0(-12.0 \text { to } 74.0)^{c}$ & 19 & $2.0(-83.0$ to 90.0$)$ & 189 & $1.0(-45.0$ to 88.0$)$ & 190 & $0.0(-18 \text { to } 19)^{c}$ & 17 & $1.0(-45.0$ to 88.0$)$ & 173 \\
\hline Percentage change & $22.2(-1800.0$ to 92.3$)$ & 208 & $40.8(-200$ to 92.3$)$ & 19 & $20.7(-1800.0$ to 88.57$)$ & 189 & $5.9(-900.0$ to 94.3$)$ & 190 & $0.0(-150.0$ to 85.7$)$ & 17 & $6.3(-900.0$ to 94.3$)$ & 173 \\
\hline $\begin{array}{l}\text { High at baseline } \\
\text { and normal at } \\
20 \text { weeks }\end{array}$ & $41(45.1 \%)$ & 91 & $9(64.3 \%)$ & 14 & $32(42.1 \%)$ & 76 & $41(47.1 \%)$ & 87 & $3(37.5 \%)$ & 8 & $38(50.0 \%)$ & 76 \\
\hline \multicolumn{13}{|l|}{$\mathrm{ESR}^{b} \mathrm{CD}$ patients } \\
\hline Absolute change & $2.0(-36.0$ to 90.0$)$ & 122 & $1.0(-8.0$ to 60.0$)$ & 8 & $2.0(-36.0$ to 90.0$)$ & 114 & $1.0(-42.0$ to 88.0$)$ & 114 & $0.0(-18.0$ to 14.0$)$ & 11 & $1.0(-42.0$ to 88.0$)$ & 103 \\
\hline Percentage change & $19.6(-1800$ to 92.3$)$ & 122 & $-14.2(-200.0$ to 92.3$)$ & 8 & $19.6(-1800.0$ to 88.6$)$ & 114 & 6.1 (-900.0 to 91.2$)$ & 114 & $0.0(-90.0$ to 85.7$)$ & 11 & $6.3(-900.0$ to 91.2$)$ & 103 \\
\hline $\begin{array}{l}\text { High at baseline } \\
\text { and normal at } \\
20 \text { weeks }\end{array}$ & $23(43.4 \%)$ & 53 & $3(75.0 \%)$ & 4 & $20(41.7 \%)$ & 48 & $25(46.3 \%)$ & 54 & $1(20.0 \%)$ & 5 & $24(49.0 \%)$ & 49 \\
\hline \multicolumn{13}{|l|}{$\mathrm{ESR}^{b}$ UC patients } \\
\hline Absolute change & $2.5(-83.0$ to 74.0$)$ & 86 & $21.0(-12.0$ to 74.0$)$ & 11 & $2.0(-83.0$ to 58.0$)$ & 75 & $0.0(-45.0$ to 65.0$)$ & 71 & $0.0(-6.0$ to 19.0$)$ & 6 & $0.0(-45.0$ to 65.0$)$ & 65 \\
\hline Percentage change & $25.0(-700.0$ to 88.6$)$ & 86 & $63.6(-34.3$ to 80.9$)$ & 11 & $22.2(-700.0$ to 88.6$)$ & 75 & $0.0(-383.3$ to 94.3$)$ & 71 & $0.0(-150.0$ to 73.1$)$ & 6 & $0.0(-383.3$ to 94.3$)$ & 65 \\
\hline $\begin{array}{l}\text { High at baseline } \\
\text { and normal at } \\
20 \text { weeks }\end{array}$ & $18(47.4 \%)$ & 38 & $6(60.0 \%)$ & 10 & $12(42.9 \%)$ & 28 & $13(46.4 \%)$ & 28 & 2 (66.6\%) & 3 & $11(45.8 \%)$ & 24 \\
\hline \multicolumn{13}{|l|}{$\mathrm{CRP}^{b}$ all patients } \\
\hline Absolute change & $1.4(-264.0$ to 209.0$)$ & 182 & $1.0(-57.0$ to 209.0$)$ & 19 & $1.7(-264.0$ to 85.0$)$ & 163 & $1.0(-108.0$ to 178.0$)$ & 176 & $2.5(-42.0$ to 29.1$)$ & 14 & $1.0(-108.0$ to 178.0$)$ & 162 \\
\hline Percentage change & $26.8(-11,945.5$ to 98.9$)$ & 182 & $50.0(-3800.0$ to 97.7$)$ & 19 & $25.0(-11,945.5$ to 98.8$)$ & 163 & 22.9 (-700.0 to 100.0$)$ & 174 & $52.0(-210.0$ to 85.6$)$ & 14 & $20.0(-700.0$ to 100.0$)$ & 160 \\
\hline $\begin{array}{l}\text { High at baseline } \\
\text { and normal after } \\
20 \text { weeks }\end{array}$ & $60(51.7 \%)$ & 116 & $7(50 \%)$ & 14 & $53(52.0 \%)$ & 102 & $65(55.1 \%)$ & 113 & $4(44.4 \%)$ & 9 & $61(58.7 \%)$ & 104 \\
\hline \multicolumn{13}{|l|}{$\mathrm{CRP}^{b} \mathrm{CD}$ patients } \\
\hline Absolute change & $2.0(-223.0$ to 85.0$)$ & 122 & $-1.0(-57.0$ to 45.0$)$ & 11 & $2.0(-223.0$ to 85.0$)$ & 111 & $1.0(-108.0$ to 67.0$)$ & 113 & $3.0(-42.0$ to 29.1$)$ & 10 & $1.0(-108.0$ to 67.0$)$ & 103 \\
\hline Percentage change & $28.8(-3800.0$ to 98.8$)$ & 122 & $-20.0(-3800.0$ to 94.5$)$ & 11 & $31.0(-3333.3$ to 98.8$)$ & 111 & 20.0 (-700.0 to 98.3$)$ & 113 & $53.3(-210.0$ to 85.6$)$ & 10 & $14.3(-700.0$ to 98.3$)$ & 103 \\
\hline $\begin{array}{l}\text { High at baseline } \\
\text { and normal at } \\
20 \text { weeks }\end{array}$ & $38(48.7 \%)$ & 78 & 2 (33.3\%) & 6 & $36(50.0 \%)$ & 72 & $41(50.6 \%)$ & 81 & 3 (42.9\%) & 7 & $38(51.4 \%)$ & 74 \\
\hline \multicolumn{13}{|l|}{$\mathrm{CRP}^{b}$ UC patients } \\
\hline Absolute change & $1.0(-264.0$ to 209.0$)$ & 59 & $22.0(-17.0$ to 209.0$)$ & 8 & $0.7(-264.0$ to 84.0$)$ & 51 & $0.5(-49.0$ to 178.0$)$ & 58 & $2.3(-7.0$ to 3.0$)$ & 4 & $0.0(-49.0$ to 178.0$)$ & 54 \\
\hline Percentage change & $23.3(-11,945.45$ to 98.8$)$ & 59 & $71.7(-37.8$ to 97.7$)$ & 8 & $6.7(-11,945.5$ to 98.8$)$ & 51 & $31.3(-700.0$ to 100.0$)$ & 56 & $50.8(-31.8$ to 75.0$)$ & 4 & $12.5(-700.0$ to 100.0$)$ & 52 \\
\hline $\begin{array}{l}\text { High at baseline } \\
\text { and normal at } \\
20 \text { weeks }\end{array}$ & $22(57.9 \%)$ & 38 & $5(62.5 \%)$ & 8 & $17(56.7 \%)$ & 30 & $22(78.6 \%)$ & 28 & $1(50.0 \%)$ & 2 & $21(80.8 \%)$ & 26 \\
\hline
\end{tabular}

NOTE. Values are given as either $n(\%)$ or medians (minimum-maximum).

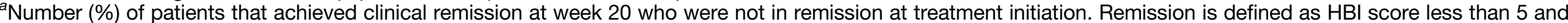

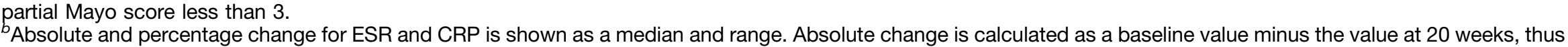

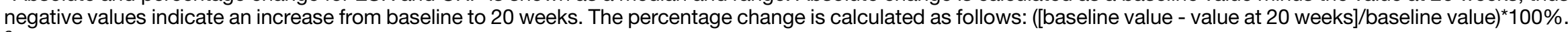

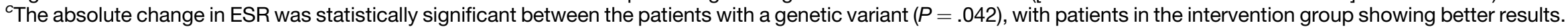

